University of Nebraska - Lincoln

DigitalCommons@University of Nebraska - Lincoln

Faculty Publications - Chemistry Department Published Research - Department of Chemistry

2009

\title{
Energy Decomposition Analysis of Covalent Bonds and Intermolecular Interactions
}

\author{
Peifeng Su \\ University of Nebraska - Lincoln, psu2@unl.edu \\ Hui Li \\ University of Nebraska - Lincoln, hli4@unl.edu
}

Follow this and additional works at: https://digitalcommons.unl.edu/chemfacpub

Part of the Chemistry Commons

Su, Peifeng and Li, Hui, "Energy Decomposition Analysis of Covalent Bonds and Intermolecular Interactions" (2009). Faculty Publications -- Chemistry Department. 22.

https://digitalcommons.unl.edu/chemfacpub/22

This Article is brought to you for free and open access by the Published Research - Department of Chemistry at DigitalCommons@University of Nebraska - Lincoln. It has been accepted for inclusion in Faculty Publications -Chemistry Department by an authorized administrator of DigitalCommons@University of Nebraska - Lincoln. 


\title{
Energy decomposition analysis of covalent bonds and intermolecular interactions
}

\author{
Peifeng Su and Hui $\mathrm{Li}^{\mathrm{a})}$ \\ Department of Chemistry, University of Nebraska-Lincoln, Nebraska 68504, USA
}

(Received 10 April 2009; accepted 8 June 2009; published online 2 July 2009)

\begin{abstract}
An energy decomposition analysis method is implemented for the analysis of both covalent bonds and intermolecular interactions on the basis of single-determinant Hartree-Fock (HF) (restricted closed shell HF, restricted open shell HF, and unrestricted open shell HF) wavefunctions and their density functional theory analogs. For HF methods, the total interaction energy from a supermolecule calculation is decomposed into electrostatic, exchange, repulsion, and polarization terms. Dispersion energy is obtained from second-order Møller-Plesset perturbation theory and coupled-cluster methods such as CCSD and CCSD(T). Similar to the HF methods, Kohn-Sham density functional interaction energy is decomposed into electrostatic, exchange, repulsion, polarization, and dispersion terms. Tests on various systems show that this algorithm is simple and robust. Insights are provided by the energy decomposition analysis into $\mathrm{H}_{2}$, methane $\mathrm{C}-\mathrm{H}$, and ethane $\mathrm{C}-\mathrm{C}$ covalent bond formation, $\mathrm{CH}_{3} \mathrm{CH}_{3}$ internal rotation barrier, water, ammonia, ammonium, and hydrogen fluoride hydrogen bonding, van der Waals interaction, DNA base pair formation, $\mathrm{BH}_{3} \mathrm{NH}_{3}$ and $\mathrm{BH}_{3} \mathrm{CO}$ coordinate bond formation, $\mathrm{Cu}$-ligand interactions, as well as $\mathrm{LiF}$, LiCl, NaF, and $\mathrm{NaCl}$ ionic interactions. (C) 2009 American Institute of Physics.
\end{abstract}

[DOI: $10.1063 / 1.3159673$ ]

\section{INTRODUCTION}

Intermolecular interaction plays an important role in determining the chemical and physical properties of a molecular system and has long been a focus of theoretical studies. A straightforward approach for interaction calculation is to perform a supermolecule calculation and subunit calculations with a size-consistent method and then derive the interaction energy by taking the energy difference. Accurate calculations of intermolecular interactions in some chemically interesting systems containing a few tens of atoms have been achieved by using second-order Møller-Plesset perturbation theory (MP2) and coupled-cluster singles, doubles, and noniterative triples $[\operatorname{CCSD}(\mathrm{T})]$ methods.

In addition to the knowledge of the total intermolecular interaction energy, it is often desirable to obtain the knowledge of its physical origins. This is especially useful in the development of force field methods that employ different functional forms to model interaction terms of different origins.

Intermolecular perturbation methods have been used to calculate intermolecular interactions since the beginning of quantum mechanics. ${ }^{1}$ The symmetry-adapted perturbation theory (SAPT) method that divides the supermolecule Hamiltonian into monomer Fock operators, monomer fluctuation operators, and an interaction operator has been popularly used. ${ }^{2}$ Recently, density functional theory based SAPT method (SAPT-DFT) was also developed. ${ }^{3}$ Usually the SAPT interaction terms are combined and interpreted as electrostatic, exchange (or exchange-repulsion), polarization,

\footnotetext{
a) Author to whom correspondence should be addressed. Electronic mail: hli4@unl.edu.
}

and dispersion energies. The interaction energies obtained from supermolecule calculations with approximate (but sizeconsistent) methods such as Hartree-Fock (HF), MP2, and $\operatorname{CCSD}(\mathrm{T})$ are interpretable with SAPT: very similar values can be obtained by using select lower-order SAPT terms. ${ }^{4}$ SAPT has been developed to study trimer interactions, ${ }^{5}$ but a general extension to many-body problems is difficult.

Pioneered by studies in Refs. 6 and 7, energy decomposition analysis (EDA) methods can also provide insights into intermolecular interactions by separating the total interaction energy computed at the HF level into various terms such as electrostatic, exchange repulsion, polarization, and charge transfer. EDA methods have been extended to study manybody systems, as was done by Chen and Gordon. ${ }^{8}$ There are many HF EDA algorithms such as the natural energy decomposition analysis (NEDA), ${ }^{9}$ the constrained space orbital variation, ${ }^{10}$ the reduced variational space (RVS) analysis, ${ }^{8,11}$ the block-localized wavefunction EDA, ${ }^{12}$ and the absolutely localized molecular orbital EDA. ${ }^{13}$ In order to complete the interaction analysis, additional supermolecule MP2 or $\operatorname{CCSD}(\mathrm{T})$ calculations are often performed to derive the dispersion energy for these HF based methods.

EDA can also be performed for DFT methods. The extended transition state (ETS) scheme is used for bond formation and bond energy analysis within the Hartree-FockSlater and DFT frames: the total interaction energy is divided into electrostatic interaction, Pauli interaction, and orbital interaction energies. ${ }^{14,15}$ Recently the NEDA and an intermolecular EDA based on fragment-localized orbitals were formulated for DFT methods. ${ }^{16}$

In this work, a simple, robust, and basis set insensitive EDA method is implemented. This method can be considered 
as an extension and modification of the methods developed by Kitaura and Morokuma, ${ }^{7}$ Ziegler and Rauk, ${ }^{17}$ and Hayes and Stone. ${ }^{18}$ The main features of the new implementation are as follows:

(1) The electrostatic, exchange, and repulsion terms are isolated, according to Hayes and Stone's method, ${ }^{18}$ from the Heitler-London interaction energy derived from an antisymmetric product of the monomer HF spin orbitals. In Kitaura and Morokuma's method ${ }^{7}$ and many other methods, exchange and repulsion are not separated. In some other methods, the Heitler-London term is not separated at all. Formulated with spin orbitals, the new implementation can deal with both closed and open shell systems described by single-determinant restricted closed shell Hartree-Fock (RHF), restricted open shell Hartree-Fock (ROHF), and unrestricted open shell Hartre-Fock (UHF) wavefunctions and, therefore, can analyze both covalent bonds and intermolecular interactions.

(2) The polarization energy is defined as the "orbital relaxation energy" on going from the monomer HF spin orbitals to the supermolecule HF spin orbitals, conceptually similar to the "electronic interaction energy" defined for the Hartree-Fock-Slater method by Ziegler and Rauk. ${ }^{17}$ This variational HF polarization energy is different from the perturbational polarization energy derived from SAPT, in which polarization and dispersion energies arise together at the second and higher orders of perturbation.

(3) The dispersion energy is derived via a supermolecule approach using size-consistent correlation methods such as MP2 and $\operatorname{CCSD}(\mathrm{T})$. This has been a standard practice in the literature.

(4) For Kohn-Sham (KS) DFT methods, the total KS interaction energy is decomposed into electrostatic, exchange, repulsion, polarization, and dispersion terms. The exchange and dispersion terms are defined using the changes in the exchange and correlation functionals on going from monomers to supermolecule.

The intermolecular interaction analysis discussed in the current paper is not dependent on or related to the choice of canonical or localized or any other type of molecular orbitals. In Sec. II below, the details of this method are described.

\section{THEORY}

\section{A. Hartree-Fock interaction}

In this subsection the decomposition of the HF interaction energy is described. As mentioned in Sec. I, the separation of the Heitler-London term is identical to those used by Hayes and Stone. ${ }^{18}$ It is necessary to introduce these equations here in order to derive similar equations for the KS method in Sec. II B.

Using a single-determinant wavefunction $\Phi$ to approximate the true wavefunction, the HF energy $E^{\mathrm{HF}}$ is obtained:

$$
E^{\mathrm{HF}}=\langle\Phi|H| \Phi\rangle,
$$

where $H$ is the Hamiltonian and $\Phi$ is formed by a set of molecular orbitals that variationally minimizes the $E^{\mathrm{HF}}$. These orbitals are the HF orbitals and are usually expanded in a set of basis functions.

If the molecular HF spin orbitals are orthonormal to each other, the corresponding energy $E^{\mathrm{HF}}$ can be written as the orbital energy integrals:

$$
\begin{aligned}
E^{\mathrm{HF}=} & \sum_{i}^{\boldsymbol{\alpha}, \boldsymbol{\beta}} h_{i}+\frac{1}{2} \sum_{i}^{\boldsymbol{\alpha}, \boldsymbol{\beta} \boldsymbol{\alpha}, \boldsymbol{\beta}} \sum_{j}\langle i i \mid j j\rangle-\frac{1}{2} \sum_{i}^{\boldsymbol{\alpha}} \sum_{j}^{\boldsymbol{\alpha}}\langle i j \mid i j\rangle \\
& -\frac{1}{2} \sum_{i}^{\boldsymbol{\beta}} \sum_{j}^{\boldsymbol{\beta}}\langle i j \mid i j\rangle+E^{\mathrm{nuc}},
\end{aligned}
$$

where $i$ and $j$ run over the occupied $\alpha$ and $\beta$ spin orbitals or both, $h_{i k}$ and $\langle i i \mid j j\rangle$ and $\langle i j \mid i j\rangle$ are one-electron and twoelectron Coulomb and exchange integrals, and $E^{\text {nuc }}$ is the nuclear repulsion energy.

It is not necessary for the molecular orbitals to be orthonormal to each other in order to minimize $E^{\mathrm{HF}}$. For example, once a set of orthonormal HF orbitals is obtained, any linear combination of the occupied HF orbitals, even nonorthonormal, still produces the same $E^{\mathrm{HF}}$ because they result in the same determinant $\Phi$ in Eq. (1). In general, if a set of nonorthonormal orbitals is used to represent the HF orbitals, the $E^{\mathrm{HF}}$ can be written as

$$
\begin{aligned}
E^{\mathrm{HF}}= & \sum_{i}^{\boldsymbol{\alpha}, \boldsymbol{\beta}} \sum_{j}^{\boldsymbol{\alpha}, \boldsymbol{\beta}} h_{i j}\left(S^{-1}\right)_{i j}+\frac{1}{2} \sum_{i}^{\boldsymbol{\alpha}, \boldsymbol{\beta}} \sum_{j}^{\boldsymbol{\alpha}, \boldsymbol{\beta}} \sum_{k}^{\boldsymbol{\alpha}, \boldsymbol{\beta}} \sum_{l}^{\boldsymbol{\alpha}, \boldsymbol{\beta}}\langle i j \mid k l\rangle \\
& \times\left(S^{-1}\right)_{i j}\left(S^{-1}\right)_{k l}-\frac{1}{2} \sum_{i}^{\boldsymbol{\alpha}} \sum_{j}^{\boldsymbol{\alpha}} \sum_{k}^{\boldsymbol{\alpha}} \sum_{l}^{\boldsymbol{\alpha}}\langle i k \mid j l\rangle \\
& \times\left(S^{-1}\right)_{i j}\left(S^{-1}\right)_{k l}-\frac{1}{2} \sum_{i}^{\boldsymbol{\beta}} \sum_{j}^{\boldsymbol{\beta}} \sum_{k}^{\boldsymbol{\beta}} \sum_{l}^{\boldsymbol{\beta}}\langle i k \mid j l\rangle \\
& \times\left(S^{-1}\right)_{i j}\left(S^{-1}\right)_{k l}+E^{\mathrm{nuc}},
\end{aligned}
$$

where $i, j, k$, and $l$ run over occupied $\alpha$ and $\beta$ spin orbitals or both and $h_{i k}$ and $\langle i j \mid k l\rangle$ and $\langle i k \mid j l\rangle$ are one- and two-electron integrals. $S^{-1}$ is the inverse of the overlap matrix $S$ of the spin orbitals. For two orbitals with opposite spins, their overlap integral is simply zero. Only for two like-spin orbitals can their overlap be possibly nonzero. If the alpha and betaspin orbitals are grouped together, the $S$ matrix is block diagonal, and so is the $S^{-1}$ matrix.

For a supermolecule $X$ consisting of monomers $A$, the total HF interaction energy is

$$
\Delta E^{\mathrm{HF}}=\left\langle\Phi_{X}\left|H_{X}\right| \Phi_{X}\right\rangle-\sum_{A}\left\langle\Phi_{A}\left|H_{A}\right| \Phi_{A}\right\rangle,
$$

where $\Phi_{X}$ and $\Phi_{A}$ are the variational single-determinant HF wavefunctions for the supermolecule $X$ and a monomer $A$. In the following it is shown that using various approximate $\mathrm{HF}$ energy expressions for the supermolecule, the total HF interaction energy $\Delta E^{\mathrm{HF}}$ can be decomposed into electrostatic, exchange, repulsion, and polarization terms:

$$
\Delta E^{\mathrm{HF}}=\Delta E^{\mathrm{ele}}+\Delta E^{\mathrm{ex}}+\Delta E^{\mathrm{rep}}+\Delta E^{\mathrm{pol}} .
$$


The electrostatic energy can be obtained by using the following approximate energy expression for a supermolecule $X$ consisting of monomers $A$ :

$$
\begin{aligned}
E_{X}^{(1)}= & \sum_{i \in X}^{\alpha, \beta} h_{i}+\frac{1}{2} \sum_{i \in X}^{\alpha, \beta} \sum_{j \in X}^{\alpha, \beta}\langle i i \mid j j\rangle \\
& -\sum_{A}\left(\frac{1}{2} \sum_{i \in A}^{\alpha} \sum_{j \in A}^{\alpha}\langle i j \mid i j\rangle+\frac{1}{2} \sum_{i \in A}^{\beta} \sum_{j \in A}^{\beta}\langle i j \mid i j\rangle\right)+E_{X}^{\mathrm{nuc}} .
\end{aligned}
$$

The spin orbitals $i$ and $j$ are the variationally optimized HF orbitals that minimize the HF energy of each monomer and are orthonormal to each other within each monomer. They are not variationally optimized to minimize the supermolecule HF energy and are not necessarily orthonormal to each other between the monomers. Compared to Eq. (2), the $E_{X}^{(1)}$ in Eq. (6) does not contain the exchange term between the monomers.

The electrostatic interaction energy between the monomers $A$ in a supermolecule $X$ is

$$
\begin{aligned}
\Delta E^{\mathrm{ele}}= & E_{X}^{(1)}-\sum_{A} E_{A}^{\mathrm{HF}}=\frac{1}{2} \sum_{i \in X}^{\alpha, \beta} \sum_{j \in X}^{\alpha, \beta}\langle i i \mid j j\rangle+E_{X}^{\mathrm{nuc}} \\
& -\sum_{A}\left(\frac{1}{2} \sum_{i \in A}^{\alpha, \beta} \sum_{j \in A}^{\alpha, \beta}\langle i i \mid j j\rangle+E_{A}^{\mathrm{nuc}}\right) .
\end{aligned}
$$

For RHF cases, the $\Delta E^{\text {ele }}$ defined in Eq. (7) is the same as in the Kitaura-Morokuma EDA and is additive for a supermolecule consisting of many monomers.

The exchange energy can be obtained by using the following approximate energy expressions for the supermolecule $X$ :

$$
\begin{aligned}
E_{X}^{(2)}= & \sum_{i \in X}^{\alpha, \beta} h_{i}+\frac{1}{2} \sum_{i \in X}^{\alpha, \beta} \sum_{j \in X}^{\alpha, \beta}\langle i i \mid j j\rangle-\frac{1}{2} \sum_{i \in X}^{\alpha} \sum_{j \in X}^{\alpha}\langle i j \mid i j\rangle \\
& -\frac{1}{2} \sum_{i \in X}^{\beta} \sum_{j \in X}^{\beta}\langle i j \mid i j\rangle+E_{X}^{\mathrm{nuc}} .
\end{aligned}
$$

Again, the spin orbitals $i$ and $j$ are the orthonormal HF spin orbitals of the monomers and are not necessarily orthonormal to each other between the monomers. Compared to Eq. (6), Eq. (8) contains the exchange terms between the monomers and has the same form as Eq. (2).

The exchange energy is defined as

$$
\begin{aligned}
\Delta E^{\mathrm{ex}}= & E_{X}^{(2)}-E_{X}^{(1)}=-\frac{1}{2} \sum_{i \in X}^{\alpha} \sum_{j \in X}^{\alpha}\langle i j \mid i j\rangle-\frac{1}{2} \sum_{i \in X}^{\beta} \sum_{j \in X}^{\beta}\langle i j \mid i j\rangle \\
& -\sum_{A}\left(\frac{1}{2} \sum_{i \in A}^{\alpha} \sum_{j \in A}^{\alpha}\langle i j \mid i j\rangle-\frac{1}{2} \sum_{i \in A}^{\beta} \sum_{j \in A}^{\beta}\langle i j \mid i j\rangle\right) .
\end{aligned}
$$

The exchange energy defined in Eq. (9) is additive for a supermolecule consisting of many monomers.

The following approximate energy expression for the supermolecule can be obtained if the monomer orbitals are used to form a single-determinant wavefunction [note that the orbital orthonormality is enforced by $S^{-1}$ as shown in Eq. (3)]:

$$
\begin{aligned}
E_{X}^{(3)}= & \sum_{i \in X}^{\alpha, \beta} \sum_{j \in X}^{\alpha, \beta} h_{i j}\left(S^{-1}\right)_{i j}+\frac{1}{2} \sum_{i \in X}^{\alpha, \beta} \sum_{j \in X}^{\alpha, \beta} \sum_{k \in X}^{\alpha, \beta} \sum_{l \in X}^{\alpha, \beta}\langle i j \mid k l\rangle \\
& \times\left(S^{-1}\right)_{i j}\left(S^{-1}\right)_{k l}-\frac{1}{2} \sum_{i \in X}^{\alpha} \sum_{j \in X}^{\alpha} \sum_{k \in X}^{\alpha} \sum_{l \in X}^{\alpha}\langle i k \mid j l\rangle \\
& \times\left(S^{-1}\right)_{i j}\left(S^{-1}\right)_{k l}-\frac{1}{2} \sum_{i \in X}^{\beta} \sum_{j \in X}^{\beta} \sum_{k \in X}^{\beta} \sum_{l \in X}^{\beta}\langle i k \mid j l\rangle \\
& \times\left(S^{-1}\right)_{i j}\left(S^{-1}\right)_{k l}+E_{X}^{\text {nuc }} .
\end{aligned}
$$

Again, $i, j, k$, and $l$ are the orthonormal HF spin orbitals of the monomers and are not necessarily orthonormal to each other between the monomers; $S^{-1}$ is the inverse of the overlap matrix $S$ of all of the monomer spin orbitals. Because the monomer spin orbitals are not necessarily orthonormal to each other between the monomers, the $S$ and $S^{-1}$ matrices are not unit matrices.

The repulsion energy is defined as

$$
\Delta E^{\mathrm{rep}}=E_{X}^{(3)}-E_{X}^{(2)} \text {. }
$$

For RHF cases, the sum of the $\Delta E^{\text {ex }}$ and $\Delta E^{\text {rep }}$ defined in Eqs. (9) and (11) is the same as the exchange-repulsion term in the Kitaura-Morokuma EDA. Because Eq. (10) enforces the simultaneous orthonormalization of all the orbitals from all monomers (by using the inverse of the supermolecule overlap matrix $S$ ), the repulsion energy is not pairwise additive for a supermolecule consisting of many monomers.

For a supermolecule $X$ consisting of monomers $A$, the HF polarization interaction energy is defined as

$$
\Delta E^{\mathrm{pol}}=E_{X}^{\mathrm{HF}}-E_{X}^{(3)},
$$

where $E_{X}^{\mathrm{HF}}$ is the HF energy of the supermolecule $X$. For RHF cases, the $\Delta E^{\text {pol }}$ defined by Eq. (12) is equivalent to the sum of the polarization, the charge transfer, and the mixing term in the Kitaura-Morokuma EDA. For a supermolecule consisting of many monomers, the $\Delta E^{\mathrm{pol}}$ is not additive.

For MP2, CCSD, and CCSD(T) methods that use singledeterminant HF wavefunctions as references, the total interaction energy can be naturally separated into HF interaction and dispersion interaction. For example, in the $\operatorname{CCSD}(\mathrm{T})$ case,

$$
\begin{aligned}
\Delta E^{\mathrm{CCSD}(\mathrm{T})} & =\Delta E^{\mathrm{HF}}+\Delta E^{\mathrm{disp}} \\
& =\Delta E^{\mathrm{HF}}+\left(\Delta E^{\mathrm{CCSD}(\mathrm{T})}-\Delta E^{\mathrm{HF}}\right),
\end{aligned}
$$

where the dispersion term $\Delta E^{\text {disp }}$ is simply the difference between the $\operatorname{CCSD}(\mathrm{T})$ and HF interaction energies. Apparently, the interaction energy terms defined by Eqs. (7), (9), and (11)-(13) are valid for the RHF, ROHF, and UHF methods.

\section{B. Kohn-Sham method}

Similar to the HF method, using a single-determinant wavefunction $\Phi$ formed by a set of orthonormal orbitals, the $\mathrm{KS}$ energy $E^{\mathrm{KS}}$ can be written as [see Eq. (2)] 


$$
\begin{aligned}
E^{\mathrm{KS}}= & \sum_{i}^{\alpha, \beta} h_{i}+\frac{1}{2} \sum_{i}^{\alpha, \beta} \sum_{j}^{\alpha, \beta}\langle i i \mid j j\rangle+E_{x}\left[\rho^{\alpha}, \rho^{\beta}\right] \\
& +E_{c}\left[\rho^{\alpha}, \rho^{\beta}\right]+E^{\mathrm{nuc}},
\end{aligned}
$$

where $h_{i}$ and $\langle i i \mid j j\rangle$ are the one- and two-electron integrals and $E^{\text {nuc }}$ is the nuclear repulsion energy, $E_{x}\left[\rho^{\alpha}, \rho^{\beta}\right]$ and $E_{c}\left[\rho^{\alpha}, \rho^{\beta}\right]$ are the exchange and correlation functionals, and $\rho^{\alpha}$ and $\rho^{\beta}$ are the alpha-spin and beta-spin electron density functions, which are the sum of the square of each occupied KS spin orbital (assume orthonormal real functions):

$$
\begin{aligned}
& \rho^{\alpha}=\sum_{i}^{\alpha} \psi_{i} \psi_{i}, \\
& \rho^{\beta}=\sum_{i}^{\beta} \psi_{i} \psi_{i} .
\end{aligned}
$$

Similar to the HF methods, it is not necessary for the KS orbitals to be orthonormal to each other in order to minimize $E^{\mathrm{KS}}$. In general, if a set of nonorthonormal orbitals is used the $E^{\mathrm{KS}}$ can be written as

$$
\begin{aligned}
E^{\mathrm{KS}}= & \sum_{i}^{\alpha, \beta} \sum_{j}^{\alpha, \beta} h_{i j}\left(S^{-1}\right)_{i j}+\frac{1}{2} \sum_{i}^{\alpha, \beta} \sum_{j}^{\alpha, \beta} \sum_{k}^{\alpha, \beta} \sum_{l}^{\alpha, \beta}\langle i j \mid k l\rangle \\
& \times\left(S^{-1}\right)_{i j}\left(S^{-1}\right)_{k l}+E_{x}\left[\rho^{\alpha}, \rho^{\beta}\right]+E_{c}\left[\rho^{\alpha}, \rho^{\beta}\right]+E^{\mathrm{nuc}} .
\end{aligned}
$$

The summations in Eq. (16) are over occupied $\alpha$ and $\beta$ spin orbitals or both; $h_{i k}$ and $\langle i k \mid r s\rangle$ are one- and two-electron integrals. The electron density functions $\rho^{\alpha}$ and $\rho^{\beta}$ in Eq. (16) must be rewritten as

$$
\begin{gathered}
\rho^{\alpha}=\sum_{i}^{\alpha} \sum_{j}^{\alpha} \psi_{i} \psi_{j}\left(S^{-1}\right)_{i j}, \\
\rho^{\beta}=\sum_{i}^{\beta} \sum_{j}^{\beta} \psi_{i} \psi_{j}\left(S^{-1}\right)_{i j} .
\end{gathered}
$$

It is trivial to show that the density functions in Eq. (17) are the same as those in Eq. (15) as long as the nonorthonormal orbitals give the same $E^{\mathrm{KS}}$. Therefore, the exchange and correlation functionals remain unchanged on going from orthornormal to nonorthonormal representations of the KS orbitals.

For a supermolecule $X$ consisting of monomers $A$, the total KS interaction energy is

$$
\Delta E^{\mathrm{KS}}=E_{X}^{\mathrm{KS}}-\sum_{A} E_{A}^{\mathrm{KS}} .
$$

In principle, if the exact exchange-correlation functionals are known, Eq. (18) gives the true interaction energy.

In the following it is shown that the total KS interaction energy $\Delta E^{\mathrm{KS}}$ can be decomposed into electrostatic, exchange, repulsion, polarization, and dispersion terms:

$$
\Delta E^{\mathrm{KS}}=\Delta E^{\mathrm{ele}}+\Delta E^{\mathrm{ex}}+\Delta E^{\mathrm{rep}}+\Delta E^{\mathrm{pol}}+\Delta E^{\mathrm{disp}} .
$$

The electrostatic energy can be obtained by using the following approximate energy expressions for the supermolecule $X$ :

$$
\begin{aligned}
E_{X}^{(1)}= & \sum_{i \in X}^{\alpha, \beta} h_{i}+\frac{1}{2} \sum_{i \in X}^{\alpha, \beta} \sum_{j \in X}^{\alpha, \beta}\langle i i \mid j j\rangle+\sum_{A} E_{x}\left[\rho_{A}^{\alpha}, \rho_{A}^{\beta}\right] \\
& +\sum_{A} E_{c}\left[\rho_{A}^{\alpha}, \rho_{A}^{\beta}\right]+E_{X}^{\mathrm{nuc}} .
\end{aligned}
$$

The spin orbitals $i$ and $j$ are the variationally optimized KS orbitals that minimize the KS energy of each monomer and are orthonormal to each other within each monomer. They are not variationally optimized to minimize the supermolecule KS energy and are not necessarily orthonormal to each other between the monomers. The exchange and correlation functionals are simply the sums of the monomer values.

The KS electrostatic interaction energy is defined as

$$
\begin{aligned}
\Delta E^{\mathrm{ele}}= & E_{X}^{(1)}-\sum_{A} E_{A}^{\mathrm{KS}}=\frac{1}{2} \sum_{i \in X}^{\alpha, \beta} \sum_{j \in X}^{\alpha, \beta}\langle i i \mid j j\rangle+E_{X}^{\mathrm{nuc}} \\
& -\sum_{A}\left(\frac{1}{2} \sum_{i \in A}^{\alpha, \beta} \sum_{j \in A}^{\alpha, \beta}\langle i i \mid j j\rangle+E_{A}^{\mathrm{nuc}}\right) .
\end{aligned}
$$

The KS exchange energy can be obtained by using the following approximate energy expression for the supermolecule $X$ :

$$
\begin{aligned}
E_{X}^{(2)}= & \sum_{i \in X}^{\alpha, \beta} h_{i}+\frac{1}{2} \sum_{i \in X}^{\alpha, \beta} \sum_{j \in X}^{\alpha, \beta}\langle i i \mid j j\rangle+E_{x}\left[\sum_{A} \rho_{A}^{\alpha}, \sum_{A} \rho_{A}^{\beta}\right] \\
& +\sum_{A} E_{c}\left[\rho_{A}^{\alpha}, \rho_{A}^{\beta}\right]+E_{X}^{\mathrm{nuc}} .
\end{aligned}
$$

Again, $i$ and $j$ are the variationally determined KS spin orbitals for the monomers and are not necessarily orthonormal to each other between the monomers.

The KS exchange interaction is defined as

$$
\Delta E^{\mathrm{ex}}=E_{X}^{(2)}-E_{X}^{(1)}=E_{x}\left[\sum_{A} \rho_{A}^{\alpha}, \sum_{A} \rho_{A}^{\beta}\right]-\sum_{A} E_{x}\left[\rho_{A}^{\alpha}, \rho_{A}^{\beta}\right] .
$$

In general, since the exchange functional $E_{x}[\rho]$ is nonlinear, $\Delta E^{\mathrm{ex}}$ is not zero.

The KS repulsion energy can be obtained by using the following approximate energy expression for the supermolecule $X$ :

$$
\begin{aligned}
E_{X}^{(3)}= & \sum_{i \in X}^{\alpha, \beta} \sum_{j \in X}^{\alpha, \beta} h_{i j}\left(S^{-1}\right)_{i j}+\frac{1}{2} \sum_{i \in X}^{\alpha, \beta} \sum_{j \in X}^{\alpha, \beta} \sum_{k \in X}^{\alpha, \beta} \sum_{l \in X}^{\alpha, \beta}\langle i j \mid k l\rangle \\
& \times\left(S^{-1}\right)_{i j}\left(S^{-1}\right)_{k l}+E_{x}\left[\rho_{X}^{\alpha *}, \rho_{X}^{\beta *}\right]+\sum_{A} E_{c}\left[\rho_{A}^{\alpha}, \rho_{A}^{\beta}\right] \\
& +E_{X}^{\mathrm{nuc}} .
\end{aligned}
$$

Again, $i, j, k$, and $l$ are the variationally determined KS spin orbitals for the monomers and are not necessarily orthonormal to each other between the monomers. Therefore, the $S$ and $S^{-1}$ matrices are not unit matrices. The $\rho_{X}^{\alpha *}$ and $\rho_{X}^{\beta *}$ in Eq. (24) are the alpha-spin and beta-spin electron density functions calculated using the orthonormalized monomer KS spin orbitals: 


$$
\begin{aligned}
& \rho_{X}^{\alpha *}=\sum_{i \in X}^{\alpha} \sum_{j \in X}^{\alpha} \psi_{i} \psi_{j}\left(S^{-1}\right)_{i j}, \\
& \rho_{X}^{\beta *}=\sum_{i \in X}^{\beta} \sum_{j \in X}^{\beta} \psi_{i} \psi_{j}\left(S^{-1}\right)_{i j} .
\end{aligned}
$$

Since $S$ and $S^{-1}$ are not unit matrices, $\rho_{X}^{\alpha *}$ and $\rho_{X}^{\beta *}$ for the supermolecule are not the respective sums of the monomer density functions:

$$
\begin{aligned}
& \rho_{X}^{\alpha^{*}} \neq \sum_{A} \rho_{A}^{\alpha}, \\
& \rho_{X}^{\beta^{*}} \neq \sum_{A} \rho_{A}^{\beta} .
\end{aligned}
$$

Clearly, the three exchange functionals appearing in Eqs. (23) and (24) are different:

$$
E_{x}\left[\rho_{X}^{\alpha *}, \rho_{X}^{\beta *}\right] \neq E_{x}\left[\sum_{A} \rho_{A}^{\alpha}, \sum_{A} \rho_{A}^{\beta}\right] \neq \sum_{A} E_{x}\left[\rho_{A}^{\alpha}, \rho_{A}^{\beta}\right] .
$$

The KS repulsion energy is defined as

$$
\Delta E^{\mathrm{rep}}=E_{X}^{(3)}-E_{X}^{(2)}
$$

The KS polarization energy can be obtained by using the following approximate energy expression for the supermolecule $X$ :

$$
\begin{aligned}
E_{X}^{(4)}= & \sum_{i \in X}^{\alpha, \beta} \sum_{j \in X}^{\alpha, \beta} h_{i j}\left(S^{-1}\right)_{i j}+\frac{1}{2} \sum_{i \in X}^{\alpha, \beta} \sum_{j \in X}^{\alpha, \beta} \sum_{k \in X}^{\alpha, \beta} \sum_{l \in X}^{\alpha, \beta}\langle i j \mid k l\rangle \\
& \times\left(S^{-1}\right)_{i j}\left(S^{-1}\right)_{k l}+E_{x}\left[\rho_{X}^{\alpha}, \rho_{X}^{\beta}\right]+\sum_{A} E_{c}\left[\rho_{A}^{\alpha}, \rho_{A}^{\beta}\right]+E_{X}^{\mathrm{nuc}} \\
= & \sum_{i \in X}^{\alpha, \beta} h_{i}+\frac{1}{2} \sum_{i \in X}^{\alpha, \beta} \sum_{j \in X}^{\alpha, \beta}\langle i i \mid j j\rangle+E_{x}\left[\rho_{X}^{\alpha}, \rho_{X}^{\beta}\right] \\
& +\sum_{A} E_{c}\left[\rho_{A}^{\alpha}, \rho_{A}^{\beta}\right]+E_{X}^{\mathrm{nuc}}
\end{aligned}
$$

where $i, j, k$, and $l$ are the variationally determined orthonormal KS spin orbitals for the supermolecule $X$ and $S^{-1}$ is a unit matrix.

The KS polarization energy is defined as

$$
\Delta E^{\mathrm{pol}}=E_{X}^{(4)}-E_{X}^{(3)} .
$$

Finally, the KS dispersion energy is defined as

$$
\Delta E^{\mathrm{disp}}=E_{X}^{\mathrm{KS}}-E_{X}^{(4)}=E_{c}\left[\rho_{X}^{\alpha}, \rho_{X}^{\beta}\right]-\sum_{A} E_{c}\left[\rho_{A}^{\alpha}, \rho_{A}^{\beta}\right],
$$

where $\rho_{X}^{\alpha}$ and $\rho_{X}^{\beta}$ are the supermolecular electron densities that minimize the KS energy of the supermolecule and $\rho_{A}^{\alpha}$ and $\rho_{A}^{\beta}$ are the monomer electron density functions that minimize the KS energy of each monomer. Apparently, Eqs. (21), (23), (28), (30), and (31) are valid for the R-KS, RO-KS, and U-KS methods.

\section{IMPLEMENTATION AND COMPUTATIONAL METHODS}

All calculations were performed with the quantum chemistry program package GAMESS ${ }^{19}$ in which the EDA method was implemented by the authors. The EDA program uses existing programs in GAMESS to perform RHF, ROHF, and UHF (and their DFT analogs) self-consistent field (SCF) calculations. MP2, CCSD, and CCSD(T) energy calculations using RHF, ROHF, and UHF references were also interfaced with the method. Most of these calculations, especially the MP2,${ }^{20} \mathrm{CCSD}$, and CCSD(T) ones, ${ }^{21}$ have been parallelized in GAMESS in previous work (by other authors) using the distributed data interface. ${ }^{22}$ However, it is noted that currently RO-CCSD is not parallelized, and CCSD/UHF is not available. The EDA calculation is always affordable as long as the supermolecule calculation is affordable at the requested level of theory, with a computing time that is two to three times longer due to the interaction analysis which involves integral transformations from the basis set to the molecular orbitals. The largest calculation that occurred in this work is the MP2/aug-cc-pVQZ calculations for a DNA base pair (30 atoms and 2600 basis functions), which took 14 days on a four-node 32-processor 128 Gbyte random access memory cluster.

The counterpoise $(\mathrm{CP})$ method proposed by Boys and Bernardi $^{23}$ for correcting the basis set superposition error (BSSE) is implemented as an option so the monomers can use the supermolecule basis set. Usually HF and MP2 calculations with the supermolecule basis set are not problematic, but DFT-SCF and CCSD iterations are sometimes divergent when the supermolecule basis set is used. Most of the calculations performed in this work used the BSSE correction.

A flow chart of the current EDA method is given in Fig. 1. The program first calculates the monomer and supermolecule HF or KS orbitals and energies at the requested level of theory. For monomers, the monomer basis sets and, optionally, the supermolecule basis set are used. If MP2 or CC calculations are requested, they will be performed immediately after the HF SCF procedure. Then it determines the intermolecular HF electrostatic and exchange interactions by virtually calculating the intermolecular Coulomb $\langle i i \mid j j\rangle$ and exchange $\langle i j \mid i j\rangle$ integrals using the monomer HF spin orbitals. This requires an integral transformation from basis functions to molecular spin orbitals. Next, the program orthornormalizes the occupied HF spin orbitals of the monomers using the $S^{-1}$ matrix and then calculates an energy, which is used to derive the HF repulsion energy. DFT interaction energies are determined in a similar manner. Finally, the interaction terms are organized and printed out.

The aug-cc-pVnZ ( $n=\mathrm{D}, \mathrm{T}, \mathrm{Q}$, and 5$)$ basis sets $^{24}$ were used. They are denoted as ACCD, ACCT, ACCQ, and ACC5 in the following discussions. If the $\mathrm{CP}$ method is used the basis sets are denoted as $\mathrm{ACCD}(\mathrm{CP})$, ACCT(CP), AC$\mathrm{CQ}(\mathrm{CP})$, and $\mathrm{ACC} 5(\mathrm{CP})$. Normally this series of basis sets is used as pure spherical harmonics, but in this work all the components were used except for a few cases specially indicated in Sec. IV. The $h$-type functions in the ACC5 basis set are not used due to the absence of the corresponding integral 


\begin{tabular}{|c|c|}
\hline $\begin{array}{c}\text { Monomer } \mathrm{E}^{\mathrm{HF}} \\
\text { RHF, ROHF, UHF }\end{array}$ & $\begin{array}{c}\text { Monomer } \mathrm{E}^{\mathrm{KS}} \\
\text { RHF, ROHF, UHF }\end{array}$ \\
\hline$\Delta \mathrm{E}^{\text {ele }} \downarrow$ & $\Delta \mathrm{E}^{\text {ele }} \downarrow$ \\
\hline $\begin{array}{l}\text { Super molecule } \mathrm{E}^{(1)} \\
\quad<\mathrm{ii} \mid \mathrm{jj}>\end{array}$ & $\begin{array}{l}\text { Super molecule } \mathrm{E}^{(1)} \\
<\mathrm{ii} \mid \mathrm{jj}>\end{array}$ \\
\hline$\Delta \mathrm{E}^{\mathrm{ex}} \downarrow$ & $\Delta \mathrm{E}^{\mathrm{ex}} \downarrow$ \\
\hline $\begin{array}{l}\text { Super molecule } \mathrm{E}^{(2)} \\
\quad<\mathrm{ij} \mid \mathrm{ij}>\end{array}$ & $\begin{array}{l}\text { Super molecule } \mathrm{E}^{(2)} \\
\mathrm{E}_{\mathrm{x}}\left[\Sigma \rho_{\mathrm{A}}\right]-\Sigma \mathrm{E}_{\mathrm{X}}\left[\rho_{\mathrm{A}}\right]\end{array}$ \\
\hline$\Delta \mathrm{E}^{\mathrm{rep}} \downarrow$ & $\Delta \mathrm{E}^{\mathrm{rep}} \downarrow$ \\
\hline $\begin{array}{l}\text { Super molecule } \mathrm{E}^{(3)} \\
\mathrm{S}^{-1}\end{array}$ & $\begin{array}{l}\text { Super molecule } \mathrm{E}^{(3)} \\
\qquad \mathrm{S}^{-1}\end{array}$ \\
\hline$\Delta \mathrm{E}^{\mathrm{pol}} \downarrow$ & $\Delta \mathrm{E}^{\mathrm{pol}} \downarrow$ \\
\hline $\begin{array}{l}\text { Super molecule } \mathrm{E}^{\mathrm{HF}} \\
\text { RHF, ROHF, UHF }\end{array}$ & $\begin{array}{c}\text { Super molecule } \mathrm{E}^{(4)} \\
\text { monomer } \Sigma \mathrm{E}_{c}\left[\rho_{\mathrm{A}}\right]\end{array}$ \\
\hline$\Delta \mathrm{E}^{\mathrm{disp}} \downarrow$ & $\Delta \mathrm{E}^{\mathrm{disp}} \downarrow$ \\
\hline $\begin{array}{c}\text { MP2 } \\
\text { CCSD, CCSD(T) }\end{array}$ & $\begin{array}{c}\text { Super molecule } \mathrm{E}^{\mathrm{KS}} \\
\mathrm{E}_{\mathrm{c}}\left[\Sigma \rho_{\mathrm{X}}\right]-\Sigma \mathrm{E}_{\mathrm{c}}\left[\rho_{\mathrm{A}}\right]\end{array}$ \\
\hline
\end{tabular}

FIG. 1. Scheme of the EDA method.

codes in GAMESS. In addition, due to the linear dependences in the large basis sets, the variational space will be automatically reduced to enhance numerical stabilities in the calculations. These will usually affect the final interaction energy by a presumably very small but unknown value. For most of the cases the MP2/ACCQ method was used to optimize the supermolecular geometry. For some large systems only the ACCT or ACCD basis sets were used. It is well known that switching from ACCT to ACCQ leads to essentially no geometric changes. Compared to ACCT and ACCQ, ACCD may produce slightly different geometries but in general the results are similar.

Two DFT methods, B3LYP (Ref. 25) and BLYP, ${ }^{26}$ were used to perform the EDA calculations in this work. All DFT methods implemented in GAMESS can be used. UHF, U-B3LYP, and U-BLYP calculations involved in this work were examined and no significant spin contaminations were found.

In this work the interaction energy between the "monomers in the supermolecule," i.e., the negative value of the equilibrium dissociation energy $D_{e}$, is discussed. Therefore, the reference for the interaction energy is the monomers that have already assumed their geometries in the supermolecule. The geometry distortion or preparation energy, zero point energy, and thermal energy are not included.

\section{RESULTS AND DISCUSSION}

\section{A. Covalent bond analysis}

\section{1. $H-H$}

As the simplest neutral molecule, $\mathrm{H}_{2}$ is used to illustrate the application of the current EDA method for bonding interaction analysis. The experimental $\mathrm{H}_{2}$ bond length of $0.7413 \AA$ is used. ${ }^{27}$ The total interaction energy computed with CCSD/ACCQ(CP) method for $\mathrm{H}_{2}$ is $-109.21 \mathrm{kcal} / \mathrm{mol}$

TABLE I. Covalent bond interaction analysis $(\mathrm{kcal} / \mathrm{mol})$.

\begin{tabular}{|c|c|c|c|c|c|c|c|}
\hline Molecule & Level of theory & $\Delta E^{\text {ele }}$ & $\Delta E^{\mathrm{ex}}$ & $\Delta E^{\text {rep }}$ & $\Delta E^{\mathrm{pol}}$ & $\Delta E^{\text {disp }}$ & $\Delta E$ \\
\hline $\mathrm{H}-\mathrm{H}$ & CCSD/ACCQ $(\mathrm{CP}) / / 0.7413 \AA$ & -1.47 & 0.00 & 0.00 & -82.35 & -25.38 & -109.21 \\
\hline \multirow{4}{*}{$\mathrm{CH}_{3}-\mathrm{H}$} & RO-CCSD/ACCQ(CP)//MP2/ACCQ & -63.59 & -77.47 & 160.66 & -113.61 & -23.83 & -117.83 \\
\hline & ROMP2/ACCQ(CP)//MP2/ACCQ & -63.59 & -77.47 & 160.66 & -113.61 & -24.74 & -118.74 \\
\hline & RO-B3LYP/ACCQ(CP)//MP2/ACCQ & -60.41 & -36.41 & 126.69 & -124.82 & -23.82 & -118.78 \\
\hline & RO-BLYP/ACCQ(CP)//MP2/ACCQ & -59.31 & -23.09 & 114.93 & -126.68 & -23.48 & -117.64 \\
\hline \multirow[t]{4}{*}{$\mathrm{BH}_{3}-\mathrm{NH}_{3}$} & $\operatorname{CCSD}(\mathrm{T}) / \mathrm{ACCQ}(\mathrm{CP}) / / \mathrm{MP} 2 / \mathrm{ACCQ}$ & -82.02 & -123.58 & 238.65 & -68.10 & -9.11 & -44.16 \\
\hline & MP2/ACCQ(CP)//MP2/ACCQ & -82.02 & -123.58 & 238.65 & -68.10 & -10.02 & -45.07 \\
\hline & B3LYP/ACCQ(CP)//MP2/ACCQ & -79.92 & -53.82 & 178.80 & -76.66 & -10.06 & -41.65 \\
\hline & BLYP/ACCQ(CP)//MP2/ACCQ & -79.76 & -32.72 & 162.71 & -78.86 & -11.18 & -39.82 \\
\hline \multirow[t]{4}{*}{$\mathrm{BH}_{3}-\mathrm{CO}$} & $\operatorname{CCSD}(\mathrm{T}) / \mathrm{ACCQ}(\mathrm{CP}) / / \mathrm{MP} 2 / \mathrm{ACCQ}$ & -70.56 & -154.03 & 303.26 & -98.59 & -15.91 & -35.83 \\
\hline & MP2/ACCQ(CP)//MP2/ACCQ & -70.56 & -154.03 & 303.26 & -98.59 & -18.36 & -38.28 \\
\hline & B3LYP/ACCQ(CP)//MP2/ACCQ & -68.46 & -65.32 & 221.78 & -115.76 & -12.04 & -39.80 \\
\hline & BLYP/ACCQ(CP)//MP2/ACCQ & -68.37 & -39.66 & 200.78 & -120.70 & -13.43 & -41.38 \\
\hline \multirow{5}{*}{$\mathrm{CH}_{3}-\mathrm{CH}_{3}$ staggered } & RO-CCSD/ACCQ (CP)//MP2/ACCQ & -147.85 & -191.13 & 400.75 & -148.84 & $-24.77^{\mathrm{a}}$ & $-111.69^{\mathrm{a}}$ \\
\hline & ROMP2/ACCQ(CP)//MP2/ACCQ & -147.85 & -191.13 & 400.75 & -148.84 & -31.82 & -118.88 \\
\hline & UMP2/ACCQ(CP)//MP2/ACCQ & -145.08 & -183.45 & 388.96 & -143.63 & -34.69 & -117.89 \\
\hline & RO-B3LYP/ACCQ(CP)//MP2/ACCQ & -137.30 & -82.61 & 298.17 & -166.24 & -23.06 & -111.04 \\
\hline & RO-BLYP/ACCQ(CP)//MP2/ACCQ & -136.31 & -51.35 & 271.38 & -169.26 & -24.07 & -109.61 \\
\hline \multirow[t]{5}{*}{$\mathrm{CH}_{3}-\mathrm{CH}_{3}$ eclipsed } & RO-CCSD/ACCQ $(\mathrm{CP})$ & -148.11 & -193.81 & 406.64 & -148.56 & $-25.09^{\mathrm{b}}$ & $-108.77^{\mathrm{b}}$ \\
\hline & ROMP2/ACCQ(CP) & -148.11 & -193.81 & 406.64 & -148.56 & -32.07 & -115.90 \\
\hline & UMP2/ACCQ(CP) & -145.35 & -186.14 & 394.87 & -143.35 & -34.94 & -114.91 \\
\hline & RO-B3LYP/ACCQ(CP) & -137.59 & -83.36 & 301.68 & -165.75 & -23.18 & -108.20 \\
\hline & RO-BLYP/ACCQ(CP) & -136.61 & -51.68 & 274.37 & -168.70 & -24.19 & -106.81 \\
\hline
\end{tabular}


(Table I), as compared to the experimental $-D_{e}$ value of $-109.5 \mathrm{kcal} / \mathrm{mol}^{27}$ The electrostatic interaction energy $\Delta E^{\text {ele }}$ between two $\mathrm{H}$ atoms is $-1.47 \mathrm{kcal} / \mathrm{mol}$. This small attraction is caused by the electron-electron charge penetration exceeding the nucleus-electron charge penetration. The exchange term $\Delta E^{\text {ex }}$ and repulsion term $\Delta E^{\text {rep }}$ between the two $\mathrm{H}$ atoms are both zero because exchange interactions only occur between like-spin electrons, and the two $1 s$ spin orbitals are already orthonormal to each other due to their opposite spins. When two $\mathrm{H}$ atoms form $\mathrm{H}_{2}$, the $1 s$ spin orbitals change shapes to form $\mathrm{H}_{2}$ molecular spin orbital, resulting in a large polarization energy $\Delta E^{\mathrm{pol}}=-82.35 \mathrm{kcal} / \mathrm{mol}$. Calculated with the CCSD/ACCQ method, which is equivalent to full configuration interaction/ACCQ in this case, the electron correlation energy for $\mathrm{H}_{2}$ (using $\mathrm{HF}$ energy as the reference) is $-25.38 \mathrm{kcal} / \mathrm{mol}$.

\section{2. $\mathrm{C}-\mathrm{H}$ bond in $\mathrm{CH}_{4}$}

A $\mathrm{C}-\mathrm{H}$ bond in $\mathrm{CH}_{4}$ was studied and the results are presented in Table I. The geometry of $\mathrm{CH}_{4}$ was optimized with the MP2/ACCQ method, which leads to a $\mathrm{C}-\mathrm{H}$ bond length of $1.084 \AA$. The $\mathrm{CH}_{4}$ is divided into a $\mathrm{CH}_{3}$ radical and a $\mathrm{H}$ atom, both described with restricted open shell wavefunctions. The ROHF/ACCQ $(\mathrm{CP})$ electrostatic energy $\Delta E^{\text {ele }}$ is $-63.59 \mathrm{kcal} / \mathrm{mol}$. The overlap between the $\mathrm{H} 1 s$ beta spin orbital and the four beta spin orbitals of $\mathrm{CH}_{3}$ results in $-77.47 \mathrm{kcal} / \mathrm{mol}$ of exchange energy but simultaneously a strong repulsion energy of $160.66 \mathrm{kcal} / \mathrm{mol}$. Forming a new $\mathrm{C}-\mathrm{H}$ bond, the orbitals change their shapes significantly and result in a polarization energy of $-113.61 \mathrm{kcal} / \mathrm{mol}$. Computed with $\operatorname{CCSD}(\mathrm{T}) / \mathrm{ACCQ}(\mathrm{CP})$, the dispersion energy is $-23.83 \mathrm{kcal} / \mathrm{mol}$, and the total interaction energy is -117.83 $\mathrm{kcal} / \mathrm{mol}$. Compared to the ROHF method, the RO-B3LYP and RO-BLYP methods produce slightly different $\Delta E^{\mathrm{ele}}$ : -63.59 for ROHF, -60.41 for RO-B3LYP, and -59.31 for RO-BLYP, all in $\mathrm{kcal} / \mathrm{mol}$. Although the $\Delta E^{\mathrm{ex}}$ and $\Delta E^{\mathrm{rep}}$ are distinctively different in the DFT and HF methods; their sum shows similarities. The RO-B3LYP and RO-BLYP $\Delta E^{\mathrm{pol}}$ are $\sim 10 \mathrm{kcal} / \mathrm{mol}$ stronger than the $\mathrm{HF}$ ones, indicating that $\mathrm{KS}$ orbitals are softer than the HF ones. The RO-B3LYP and RO-BLYP $\Delta E^{\text {disp }}$ and total bond energies are similar to those from the RO-CCSD calculation. Considering preparation energy, zero point energy, and thermal energy, Kass et al. obtained $104.2 \mathrm{kcal} / \mathrm{mol}$ for the $\mathrm{CH}_{3}-\mathrm{H}$ dissociation enthalpy at $298 \mathrm{~K}^{28}$

\section{3. $\mathrm{BH}_{3}-\mathrm{CO}$ and $\mathrm{BH}_{3}-\mathrm{NH}_{3}$}

$\mathrm{BH}_{3}$ forms very strong coordinate covalent bonds with $\mathrm{CO}$ and $\mathrm{NH}_{3}$. Many interaction analyses, most of which have a focus on the charge-transfer interactions, can be found in the literature for these molecules. ${ }^{9,12,29}$ Here $\mathrm{BH}_{3} \cdots \mathrm{CO}$ and $\mathrm{BH}_{3} \cdots \mathrm{NH}_{3}$ are used as examples to illustrate the role of the polarization energy in the formation of these strong coordinate bonds between main group elements. The MP2/ACCQ optimized $\mathrm{B}-\mathrm{C}$ distance in $\mathrm{BH}_{3} \cdots \mathrm{CO}$ is $1.539 \AA$, as compared to an experimental value of $1.534 \pm 0.01 \AA$ reported by Venkatachar et $a l .{ }^{30}$ The total $\operatorname{CCSD}(\mathrm{T}) / \mathrm{ACCQ}(\mathrm{CP})$ interaction energy between $\mathrm{BH}_{3}$ and $\mathrm{CO}$ is $-36.39 \mathrm{kcal} / \mathrm{mol}$, with $\Delta E^{\mathrm{ele}}=-70.53, \Delta E^{\mathrm{ex}}=-154.02, \Delta E^{\mathrm{rep}}=+303.20, \Delta E^{\mathrm{pol}}$ $=-98.63$, and $\Delta E^{\mathrm{disp}}=-16.41 \mathrm{kcal} / \mathrm{mol}$ (Table I). The MP2/ ACCQ optimized B-N distance in $\mathrm{BH}_{3} \cdots \mathrm{NH}_{3}$ is $1.6470 \AA$, as compared to an experimental value of $1.6576 \pm 0.016 \AA$ reported by Thorne et al. $^{31}$ The total $\operatorname{CCSD}(\mathrm{T}) / \mathrm{ACCQ}(\mathrm{CP})$ interaction energy between $\mathrm{BH}_{3}$ and $\mathrm{NH}_{3}$ is $-44.42 \mathrm{kcal} /$ mol, with $\Delta E^{\mathrm{ele}}=-82.04, \Delta E^{\mathrm{ex}}=-123.60, \Delta E^{\mathrm{rep}}=+238.67$, $\Delta E^{\mathrm{pol}}=-68.10$, and $\Delta E^{\mathrm{disp}}=-9.35 \mathrm{kcal} / \mathrm{mol}$ (Table I). The relatively large $\Delta E^{\text {pol }}$ values suggest that the orbitals undergo significant change in their shapes, which is typical in the formation of a covalent bond. The bond energy in $\mathrm{BH}_{3} \cdots \mathrm{NH}_{3}$ is stronger than that in $\mathrm{BH}_{3} \cdots \mathrm{CO}$ by $8.03 \mathrm{kcal} /$ mol as predicted by the $\operatorname{CCSD}(\mathrm{T}) / \mathrm{ACCQ}(\mathrm{CP})$ calculation. This can be simply explained by the fact that $\mathrm{NH}_{3}$ has a relatively large dipole while $\mathrm{CO}$ has almost no dipole: the $\Delta E^{\text {elec }}$ in $\mathrm{BH}_{3} \cdots \mathrm{NH}_{3}$ is stronger than that in $\mathrm{BH}_{3} \cdots \mathrm{CO}$ by $11.51 \mathrm{kcal} / \mathrm{mol}$. Compared to $\operatorname{CCSD}(\mathrm{T}), \mathrm{MP} 2$ overestimates the bond energies by 0.89 and $2.45 \mathrm{kcal} / \mathrm{mol}$ for $\mathrm{BH}_{3} \cdots \mathrm{NH}_{3}$ and $\mathrm{BH}_{3} \cdots \mathrm{CO}$. B3LYP and BLYP methods underestimate the bond energy by $2-4 \mathrm{kcal} / \mathrm{mol}$ for $\mathrm{BH}_{3} \cdots \mathrm{NH}_{3}$ but overestimate the bond energy by $4-6 \mathrm{kcal} / \mathrm{mol}$ for $\mathrm{BH}_{3} \cdots \mathrm{CO}$ (Table I). More data for $\mathrm{BH}_{3} \cdots \mathrm{NH}_{3}$ and $\mathrm{BH}_{3} \cdots \mathrm{CO}$ can be found in Table $\mathrm{S} 1 .^{32}$

\section{B. Ethane internal rotation barrier}

Staggered ethane ( $s$-ethane) is lower in energy than eclipsed ethane ( $e$-ethane) by $\sim 2.9 \mathrm{kcal} / \mathrm{mol}$. The origin of this energy difference is studied using the EDA method. The geometry of $s$-ethane was optimized with the MP2/ACCQ method, and the geometry of $e$-ethane was obtained from the optimized $s$-ethane by rotating the $\mathrm{H}-\mathrm{C}-\mathrm{C}-\mathrm{H}$ dihedral angle from $60^{\circ}$ to $0^{\circ}$ while holding the internal geometries of the two $\mathrm{CH}_{3}$ groups and the $\mathrm{C}-\mathrm{C}$ distance of $1.5211 \AA$ unchanged. EDA calculations were performed with two $\mathrm{CH}_{3}$ neutral radicals as the monomers. Since the staggered and eclipsed forms are constructed from exactly the same $\mathrm{CH}_{3}$ groups, their final energy difference can be understood from the $\mathrm{CH}_{3}-\mathrm{CH}_{3}$ interaction energies.

At the ROHF/ACCQ $(\mathrm{CP})$ level, the $\mathrm{CH}_{3}-\mathrm{CH}_{3}$ electrostatic interaction $\Delta E^{\text {ele }}$ in $s$ - and $e$-ethane are -147.85 and $-148.11 \mathrm{kcal} / \mathrm{mol}$, differing by only $0.26 \mathrm{kcal} / \mathrm{mol}$. The $\mathrm{CH}_{3}-\mathrm{CH}_{3}$ exchange interactions $\Delta E^{\mathrm{ex}}$ in $s$ - and $e$-ethane are -191.13 and $-193.81 \mathrm{kcal} / \mathrm{mol}$, differing by $2.68 \mathrm{kcal} / \mathrm{mol}$ due to the more orbital overlap between the $\mathrm{CH}_{3}$ groups in $e$-ethane. However, the $\mathrm{CH}_{3}-\mathrm{CH}_{3}$ repulsion interactions $\Delta E^{\text {rep }}$ in $s$ - and $e$-ethane are 400.75 and $406.64 \mathrm{kcal} / \mathrm{mol}$, differing by $5.89 \mathrm{kcal} / \mathrm{mol}$. This is again due to the more orbital overlap between the $\mathrm{CH}_{3}$ groups in $e$-ethane. The polarization energies $\Delta E^{\mathrm{pol}}$ for $s$ - and $e$-ethane are -148.84 and $-148.56 \mathrm{kcal} / \mathrm{mol}$, respectively, differing by only $0.28 \mathrm{kcal} / \mathrm{mol}$. Computed with RO-CCSD/ACCT(CP), the dispersion interaction $\Delta E^{\text {disp }}$ between the $\mathrm{CH}_{3}$ groups in $s$ and $e$-ethane are -23.09 and $-23.36 \mathrm{kcal} / \mathrm{mol}$, respectively, differing by $0.27 \mathrm{kcal} / \mathrm{mol}$. Using the corrections in $\Delta E^{\text {disp }}$ obtained from the ROMP2/ACCT(CP) and ROMP2/ $\mathrm{ACCQ}(\mathrm{CP})$ results (Table $\mathrm{S} 2^{32}$ ), the $\mathrm{RO}-\mathrm{CCSD}(\mathrm{T}) /$ 
TABLE II. Water cluster interactions ( $\mathrm{kcal} / \mathrm{mol})$.

\begin{tabular}{|c|c|c|c|c|c|c|c|}
\hline Cluster size & Level of theory & $\Delta E^{\text {ele }}$ & $\Delta E^{\mathrm{ex}}$ & $\Delta E^{\mathrm{rep}}$ & $\Delta E^{\mathrm{pol}}$ & $\Delta E^{\mathrm{disp}}$ & $\Delta E$ \\
\hline \multirow[t]{3}{*}{ Dimer } & CCSD(T)/ACCQ(CP)//MP2/ACCQ & -8.41 & -8.85 & 16.01 & -2.38 & -1.33 & -4.95 \\
\hline & MP2/ACCQ(CP)//MP2/ACCQ & -8.41 & -8.85 & 16.01 & -2.38 & -1.28 & -4.91 \\
\hline & MP2/ACC5(CP)//MP2/ACCQ & -8.41 & -8.83 & 15.99 & -2.38 & -1.30 & -4.92 \\
\hline \multirow[t]{4}{*}{ Trimer } & $\operatorname{CCSD}(\mathrm{T}) / \mathrm{ACCT}(\mathrm{CP}) / / \mathrm{MP} 2 / \mathrm{ACCQ}$ & -28.37 & -34.48 & 62.80 & -10.69 & -4.60 & -15.34 \\
\hline & MP2/ACCT(CP)//MP2/ACCQ & -28.37 & -34.48 & 62.80 & -10.69 & -4.61 & -15.35 \\
\hline & MP2/ACCQ(CP)//MP2/ACCQ & -28.39 & -34.45 & 62.74 & -10.72 & -5.09 & -15.90 \\
\hline & MP2/ACC5(CP)//MP2/ACCQ & -28.38 & -34.44 & 62.73 & -10.72 & -5.15 & -15.96 \\
\hline \multirow[t]{4}{*}{ Tetramer } & $\mathrm{CCSD}(\mathrm{T}) / \mathrm{ACCT}(\mathrm{CP}) / / \mathrm{MP} 2 / \mathrm{ACCQ}$ & -52.04 & -67.16 & 124.19 & -24.97 & -7.16 & -27.13 \\
\hline & MP2/ACCT(CP)//MP2/ACCQ & -52.04 & -67.16 & 124.19 & -24.97 & -7.34 & -27.31 \\
\hline & MP2/ACCQ(CP)//MP2/ACCQ & -52.03 & -67.10 & 124.09 & -25.01 & -8.17 & -28.22 \\
\hline & MP2/ACC5(CP)//MP2/ACCQ & -52.02 & -67.08 & 124.06 & -25.01 & -8.27 & -28.33 \\
\hline
\end{tabular}

$\mathrm{ACCQ}(\mathrm{CP}) \Delta E^{\text {disp }}$ in the $s$ - and $e$-ethane are -24.77 and $-25.09 \mathrm{kcal} / \mathrm{mol}$, respectively, differing by only $0.32 \mathrm{kcal} /$ mol.

Therefore, from the $\mathrm{CH}_{3}-\mathrm{CH}_{3}$ interaction point of view, the main reason for $e$-ethane being less stable than $s$-ethane is their difference in the repulsion energy. Attenuated by the changes in the exchange, electrostatic, polarization, and dispersion energies, $e$-ethane is higher in energy by $2.92 \mathrm{kcal} /$ mol than $s$-ethane, in excellent agreement with an experimental value of $2.90 \pm 0.03 \mathrm{kcal} / \mathrm{mol} .^{33}$ Clearly, electrostatic and dispersion interactions favor $e$-ethane, while polarization favors $s$-ethane. These results are consistent with the earlier results obtained by Sovers et al. and the recent results obtained by Mo and Gao. ${ }^{34}$

Calculations with ROMP2, UMP2, RO-B3LYP, and ROBLYP methods lead to essentially the same conclusion, although the two MP2 methods give total interaction energies that are $\sim 7 \mathrm{kcal} / \mathrm{mol}$ stronger than those predicted with RO-CCSD and the two DFT methods (Table I). This is simply a fact that for $\mathrm{CH}_{3}$ radical, which is an open shell system, MP2 predicts less amount of correlation energy than does CCSD, while for the $\mathrm{CH}_{3}-\mathrm{CH}_{3}$ neutral closed shell molecule, MP2 and CCSD predict more similar correlation energies. Therefore, if the absolute value of the bond energy is of concern, open shell EDA calculations should be performed with CCSD or CCSD(T) methods. For $\mathrm{C}-\mathrm{H}$ and $\mathrm{C}-\mathrm{C}$ bonds, B3LYP and BLYP can predict $\Delta E^{\text {disp }}$ that are in excellent agreement with CCSD.

For comparison, the results of a combined charge and energy decomposition (ETS-NOCV, in the ADF software package) calculation for $s$-ethane performed by Mitoraj et $a .^{15}$ are $\Delta E_{\text {elstat }}=-129.3, \Delta E_{\text {Pauli }}=+205.9$, and $\Delta E_{\text {orb }}$ $=-187.7$, with a $\Delta E_{\text {total }}=111.2 \mathrm{kcal} / \mathrm{mol}$. Although the ETSNOCV energy decomposition scheme is different from the current EDA scheme, the interaction energy terms show some connections and similarities. For example, their $\Delta E_{\text {elstat }}=-129.3 \mathrm{kcal} / \mathrm{mol}$ is close to the $\Delta E^{\text {ele }}$ $=-137.30 \mathrm{kcal} / \mathrm{mol}$ from this work, their $\Delta E_{\text {Pauli }}$ $=+205.9 \mathrm{kcal} / \mathrm{mol}$ is close to the sum of $\Delta E^{\mathrm{ex}}+\Delta E^{\text {rep }}$ $=+215.56 \mathrm{kcal} / \mathrm{mol}$ from this work, and their $\Delta E_{\text {orb }}$ $=-187.7 \mathrm{kcal} / \mathrm{mol}$ is very close to $\Delta E^{\mathrm{pol}}+\Delta E^{\text {disp }}$ $=-189.3 \mathrm{kcal} / \mathrm{mol}$ from this work, as shown in Table I by the RO-B3LYP/ACCQ(CP) data. The differences are caused by the differences in the energy decomposition schemes, the differences in the exchange-correlation functionals, and the differences in $s$-ethane geometries and the basis sets.

\section{Water dimer, trimer, and tetramer}

Water clusters have been studied using quantum chemical methods for a long time. ${ }^{35,36}$ Here the results of EDA calculations for water dimer, trimer, and tetramer are presented and discussed (Tables II and III). The geometries of the linear water dimer, the up-up-down cyclic trimer, and the up-down-up-down cyclic tetramer (Fig. 2) were optimized with the MP2/ACCQ method. EDA calculations were performed with the ACCD, ACCT, ACCQ, and ACC5 basis sets. As is well known, the differences between the MP2 and $\operatorname{CCSD}(\mathrm{T})$ calculated interaction energies for water clusters are relatively small $(<0.2 \mathrm{kcal} / \mathrm{mol})$ due to the cancellation of different types of errors in the MP2 method (Table III and Table $\mathrm{S}^{32}$ ).

With $\Delta E^{\text {ele }}=-8.41, \Delta E^{\mathrm{ex}}=-8.85, \Delta E^{\mathrm{rep}}=+16.01, \Delta E^{\mathrm{pol}}$ $=-2.38$ and $\Delta E^{\text {disp }}=-1.33 \mathrm{kcal} / \mathrm{mol}$, the $\operatorname{CCSD}(\mathrm{T}) /$ $\mathrm{ACCQ}(\mathrm{CP}) / / \mathrm{MP} 2 / \mathrm{ACCQ}$ water dimer interaction energy is $-4.95 \mathrm{kcal} / \mathrm{mol}$ (Table II), close to the estimated CCSD(T)/ complete basis set (CBS) results -5.01 or $-5.02 \mathrm{kcal} / \mathrm{mol}$ in the literature. ${ }^{37,38}$ With $\Delta E^{\text {ele }}=-28.38, \Delta E^{\text {ex }}=-34.44, \Delta E^{\text {rep }}$ $=+62.73, \Delta E^{\mathrm{pol}}=-10.72$, and $\Delta E^{\mathrm{disp}}=-5.15 \mathrm{kcal} / \mathrm{mol}$, the $\mathrm{MP} 2 / \mathrm{ACC} 5(\mathrm{CP}) / / \mathrm{MP} 2 / \mathrm{ACCQ}$ water trimer interaction energy is $-15.96 \mathrm{kcal} / \mathrm{mol}$ (Table II), close to the estimated MP2/CBS results of -15.80 to $-15.82 \mathrm{kcal} / \mathrm{mol}^{36,39}$ The $\operatorname{CCSD}(\mathrm{T}) / \mathrm{ACCT}(\mathrm{CP})$ and MP2/ACCT(CP) results are almost identical (Table II), so it is likely that the $\operatorname{CCSD}(\mathrm{T}) /$ CBS and MP2/CBS results are very similar. Indeed, the estimated MP2/CBS and $\operatorname{CCSD}(\mathrm{T}) / \mathrm{CBS}$ in the literature are -15.80 and $-15.82 \mathrm{kcal} / \mathrm{mol}$, almost identical. ${ }^{39}$

With $\Delta E^{\text {ele }}=-52.02, \Delta E^{\mathrm{ex}}=-67.08, \Delta E^{\mathrm{rep}}=+124.06$, $\Delta E^{\mathrm{pol}}=-25.01$, and $\Delta E^{\mathrm{disp}}=-8.09 \mathrm{kcal} / \mathrm{mol}$, the $\mathrm{MP} 2 /$ $\mathrm{ACC} 5(\mathrm{CP}) / / \mathrm{MP} 2 / \mathrm{ACCQ}$ water tetramer interaction energy is $-28.33 \mathrm{kcal} / \mathrm{mol}$ (Table II), close to the estimated MP2/CBS result of $-27.63 \mathrm{kcal} / \mathrm{mol}^{36}$ According to Table II, the $\operatorname{CCSD}(\mathrm{T}) / \mathrm{ACCT}(\mathrm{CP})$ tetramer interaction energy is smaller than the MP2/ACCT(CP) value by $0.18 \mathrm{kcal} / \mathrm{mol}$, so it is likely that the $\operatorname{CCSD}(\mathrm{T}) / \mathrm{CBS}$ value is smaller than the MP2/ $\mathrm{CBS}$ value by the same amount.

An interesting issue is the pairwise additivity of the interaction terms in many-body systems. As discussed, the 
TABLE III. Many-body effects in water tetramer (kcal/mol).

\begin{tabular}{|c|c|c|c|c|c|c|c|}
\hline Pair & Level of theory & $\Delta E^{\text {ele }}$ & $\Delta E^{\mathrm{ex}}$ & $\Delta E^{\text {rep }}$ & $\Delta E^{\mathrm{pol}}$ & $\Delta E^{\text {disp }}$ & $\Delta E$ \\
\hline Pair 1,2 & MP2/ACC5 & -12.24 & -16.69 & 31.00 & -4.57 & -2.09 & -4.59 \\
\hline Pair 1,3 & MP2/ACC5 & -1.55 & -0.20 & 0.33 & -0.07 & -0.20 & -1.70 \\
\hline Pair 1, 4 & MP2/ACC5 & -12.25 & -16.71 & 31.03 & -4.57 & -2.09 & -4.59 \\
\hline Pair 2, 3 & MP2/ACC5 & -12.19 & -16.59 & 30.81 & -4.54 & -2.08 & -4.60 \\
\hline Pair 2, 4 & MP2/ACC5 & -1.55 & -0.20 & 0.32 & -0.07 & -0.20 & -1.69 \\
\hline Pair 3, 4 & MP2/ACC5 & -12.23 & -16.68 & 30.98 & -4.57 & -2.09 & -4.59 \\
\hline Pairwise sum & & -52.01 & -67.07 & 124.47 & -18.39 & -8.75 & -21.76 \\
\hline Tetramer $1,2,3,4$ & MP2/ACC5 & -52.01 & -67.07 & 124.05 & -25.03 & -8.79 & -28.85 \\
\hline Many-body effects & & 0.00 & 0.00 & -0.42 & -6.64 & -0.04 & -7.09 \\
\hline Pair 1,2 & $\mathrm{MP} 2 / \mathrm{ACC} 5(\mathrm{CP})$ & -12.24 & -16.69 & 31.00 & -4.56 & -1.96 & -4.46 \\
\hline Pair 1, 3 & $\mathrm{MP} 2 / \mathrm{ACC} 5(\mathrm{CP})$ & -1.55 & -0.20 & 0.33 & -0.07 & -0.18 & -1.68 \\
\hline Pair 1,4 & $\mathrm{MP} 2 / \mathrm{ACC} 5(\mathrm{CP})$ & -12.25 & -16.71 & 31.03 & -4.57 & -1.96 & -4.46 \\
\hline Pair 2, 3 & $\mathrm{MP} 2 / \mathrm{ACC} 5(\mathrm{CP})$ & -12.19 & -16.59 & 30.81 & -4.54 & -1.95 & -4.47 \\
\hline Pair 2, 4 & $\mathrm{MP} 2 / \mathrm{ACC} 5(\mathrm{CP})$ & -1.55 & -0.20 & 0.32 & -0.07 & -0.18 & -1.68 \\
\hline Pair 3, 4 & $\mathrm{MP} 2 / \mathrm{ACC} 5(\mathrm{CP})$ & -12.24 & -16.68 & 30.98 & -4.56 & -1.96 & -4.46 \\
\hline Pairwise sum & & -52.02 & -67.08 & 124.47 & -18.37 & -8.19 & -21.21 \\
\hline Tetramer 1, 2, 3, 4 & $\mathrm{MP} 2 / \mathrm{ACC} 5(\mathrm{CP})$ & -52.02 & -67.08 & 124.06 & -25.01 & -8.27 & -28.33 \\
\hline Many-body effects & & 0.00 & 0.00 & -0.41 & -6.64 & -0.08 & -7.12 \\
\hline
\end{tabular}

electrostatic and exchange terms in the EDA scheme are pairwise additive, while repulsion, polarization, and dispersion are not. EDA calculations were performed for the six pairs of dimers in the water tetramer (Fig. 2) at the MP2/ ACC5 level of theory, with and without BSSE corrections (Table III). ACC5 is used because it is almost a CBS for the system so the pairwise additivity under examination is close to that at the CBS limit. As expected, the sums of the pairwise electrostatic and exchange energies in the six dimers are, respectively, the same for the tetramer. For the BSSE uncorrected and corrected cases, the sums of the pairwise dimer repulsion energies are 0.42 and $0.41 \mathrm{kcal} / \mathrm{mol}$ more repulsive than that for the actual tetramer and the sums of the dimer dispersion energies are 0.04 and $0.08 \mathrm{kcal} / \mathrm{mol}$ less attractive than that for the actual tetramer. So, these two
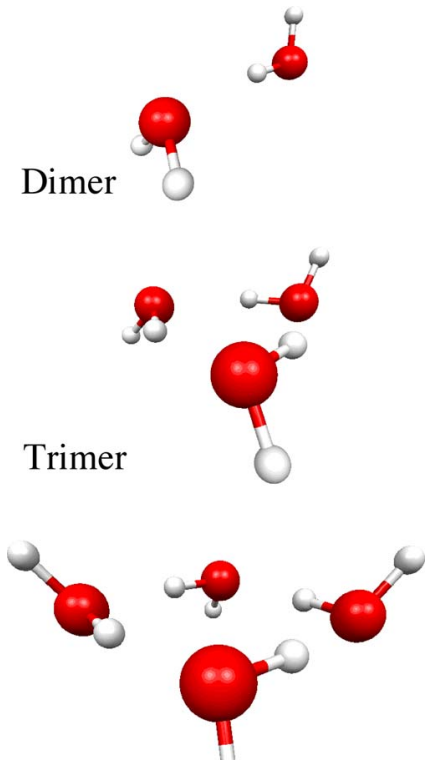

Tetramer

FIG. 2. MP2/ACCQ optimized water dimer, trimer, and tetramer. terms, especially the dispersion term, are roughly additive. As expected, the polarization energy is not additive at all: the sum of the dimer polarization energy is $6.64 \mathrm{kcal} / \mathrm{mol}$ less attractive than that in the tetramer. Clearly, the total manybody effect $(\sim 7.1 \mathrm{kcal} / \mathrm{mol})$ is mainly due to the polarization energy (Table III).

\section{Nonbonding interaction analysis}

The results of EDA calculations for some typical nonbonding interactions are presented in Table IV. These cases are selected because they are often used for comparisons in the literature.

\section{1. $\mathrm{He} \cdots \mathrm{He}$}

EDA analysis for helium dimer was performed with $\operatorname{CCSD}(\mathrm{T}) / \mathrm{ACC} 5(\mathrm{CP})$ at a $\mathrm{He}-\mathrm{He}$ distance of $2.9634 \AA$ (5.60 bohrs), which is widely used in the literature for comparison. The $\Delta E^{\text {ele }}$ is $-0.0031 \mathrm{kcal} / \mathrm{mol}$, reflecting the fact that there is some orbital overlapping between the two $\mathrm{He}$ atoms at this separation. This fact is again shown by some nonzero $\Delta E^{\mathrm{ex}}(-0.0295 \mathrm{kcal} / \mathrm{mol})$ and $\Delta E^{\text {rep }}$ $(+0.0519 \mathrm{kcal} / \mathrm{mol})$. The $\Delta E^{\mathrm{pol}}$ is only $-0.0009 \mathrm{kcal} / \mathrm{mol}$, indicating that the $\mathrm{He}$ orbitals do not change much in forming a dimer. As is well known, the main driving force for the formation of a $\mathrm{He}$ dimer is the $\Delta E^{\text {disp }}$, which is $-0.0381 \mathrm{kcal} / \mathrm{mol}$ as calculated with $\operatorname{CCSD}(\mathrm{T}) / \mathrm{ACC} 5(\mathrm{CP})$. The total $\mathrm{CCSD}(\mathrm{T}) / \mathrm{ACC} 5(\mathrm{CP})$ interaction energy is $-0.0198 \mathrm{kcal} / \mathrm{mol}$ (Table IV), as compared to one of the most accurate results of $-0.02186 \mathrm{kcal} / \mathrm{mol}^{40}$

\section{2. $\mathrm{Be} \cdots \mathrm{Be}$}

EDA analysis was performed for $\mathrm{Be}$ dimer at the $\operatorname{CCSD}(\mathrm{T}) / \mathrm{ACC} 5(\mathrm{CP})$ level of theory at the experimental Be-Be distance of $2.45 \AA \AA^{41}$ The $\Delta E^{\text {ele }}$ is $-18.56 \mathrm{kcal} / \mathrm{mol}$, indicating that there is a significant orbital overlapping between the two Be atoms. Such an overlap leads to $\Delta E^{\text {ex }}$ 
TABLE IV. Nonbonding interaction $(\mathrm{kcal} / \mathrm{mol})$.

\begin{tabular}{|c|c|c|c|c|c|c|c|}
\hline Molecule & Level of theory & $\Delta E^{\text {ele }}$ & $\Delta E^{\mathrm{ex}}$ & $\Delta E^{\text {rep }}$ & $\Delta E^{\mathrm{pol}}$ & $\Delta E^{\mathrm{disp}}$ & $\Delta E$ \\
\hline $\mathrm{He} \cdots \mathrm{He}$ & $\operatorname{CCSD}(\mathrm{T}) / \mathrm{ACC} 5(\mathrm{CP}) / / 2.9634 \AA$ & -0.0031 & -0.0295 & 0.0519 & -0.0009 & -0.0381 & -0.0198 \\
\hline $\mathrm{Be} \cdots \mathrm{Be}$ & $\mathrm{CCSD}(\mathrm{T}) / \mathrm{ACC} 5(\mathrm{CP}) / / 2.4500 \AA$ & -18.56 & -63.06 & 110.07 & -20.94 & -9.45 & -1.94 \\
\hline $\mathrm{CO}_{2} \cdots \mathrm{CO}_{2}$ & $\mathrm{CCSD}(\mathrm{T}) / \mathrm{ACCQ}(\mathrm{CP}) / / \mathrm{MP} 2 / \mathrm{ACCQ}$ & -1.76 & -2.46 & 4.31 & -0.28 & $-1.26^{\mathrm{a}}$ & $-1.45^{\mathrm{a}}$ \\
\hline $\mathrm{C}_{6} \mathrm{H}_{6} \cdots \mathrm{H}_{2} \mathrm{O}$ & $\operatorname{CCSD}(\mathrm{T}) / \mathrm{ACCQ}(\mathrm{CP}) / / \mathrm{MP} 2 / \mathrm{ACCT}$ & -3.48 & -6.54 & 11.02 & -1.33 & $-2.83^{\mathrm{b}}$ & $-3.16^{\mathrm{b}}$ \\
\hline $\mathrm{C}_{6} \mathrm{H}_{6} \cdots \mathrm{C}_{6} \mathrm{H}_{6}$ & $\operatorname{CCSD}(\mathrm{T}) / \mathrm{ACCT}(\mathrm{CP}) / / \mathrm{MP} 2 / \mathrm{ACCD}$ & -3.55 & -13.72 & 22.26 & -1.26 & $-6.05^{\mathrm{c}}$ & $-2.31^{\mathrm{c}}$ \\
\hline AT & $\mathrm{CCSD}(\mathrm{T}) / \mathrm{ACCQ}(\mathrm{CP}) / / \mathrm{MP} 2 / \mathrm{ACCD}$ & -30.35 & -40.21 & 74.13 & -14.02 & $-6.47^{\mathrm{d}}$ & $-16.92^{\mathrm{d}}$ \\
\hline GC & $\operatorname{CCSD}(\mathrm{T}) / \mathrm{ACCQ}(\mathrm{CP}) / / \mathrm{MP} 2 / \mathrm{ACCD}$ & -47.95 & -52.95 & 97.47 & -22.52 & $-6.17^{\mathrm{e}}$ & $-32.12^{\mathrm{e}}$ \\
\hline $\mathrm{HF} \cdots \mathrm{HF}$ & $\operatorname{CCSD}(\mathrm{T}) / \mathrm{ACC} 5(\mathrm{CP}) / / \mathrm{MP} 2 / \mathrm{ACCQ}$ & -6.76 & -5.71 & 10.86 & -2.23 & -0.72 & -4.56 \\
\hline $\mathrm{NH}_{3} \cdots \mathrm{H}_{2} \mathrm{O}$ & $\operatorname{CCSD}(\mathrm{T}) / \mathrm{ACCQ}(\mathrm{CP}) / / \mathrm{MP} 2 / \mathrm{ACCQ}$ & -11.88 & -14.44 & 25.95 & -4.07 & -2.00 & -6.44 \\
\hline $\mathrm{NH}_{4}{ }^{+} \cdots \mathrm{H}_{2} \mathrm{O}$ & $\mathrm{CCSD}(\mathrm{T}) / \mathrm{ACCQ}(\mathrm{CP}) / / \mathrm{MP} 2 / \mathrm{ACCQ}$ & -25.38 & -18.56 & 36.80 & -11.80 & -1.86 & -20.79 \\
\hline
\end{tabular}

${ }^{2} \Delta E^{\text {disp }}$ is the MP2/ACCQ(CP) value corrected by $-0.07 \mathrm{kcal} / \mathrm{mol}$ from MP2/ACCT(CP) to CCSD(T)/ACCT(CP).

${ }^{\mathrm{b}} \Delta E^{\text {disp }}$ is the MP2/ACCQ(CP) value corrected by $+0.33 \mathrm{kcal} / \mathrm{mol}$ from MP2/ACCD(CP) to CCSD (T)/ACCD (CP).

${ }^{\mathrm{c}} \Delta E^{\text {disp }}$ is the MP2/ACCT(CP) value corrected by $+1.22 \mathrm{kcal} / \mathrm{mol}$ from MP2/CCD to CCSD(T)/CCD.

${ }^{\mathrm{d}} \Delta E^{\text {disp }}$ is the MP2 $/ \mathrm{ACCQ}(\mathrm{CP})$ value corrected by $+0.21 \mathrm{kcal} / \mathrm{mol}$ from MP2 $/ \mathrm{CCD}$ to CCSD(T) $/ \mathrm{CCD}$.

${ }^{\mathrm{e}} \Delta E^{\mathrm{disp}}$ is the MP2/ACCQ $(\mathrm{CP})$ value corrected by $-0.01 \mathrm{kcal} / \mathrm{mol}$ from MP2/CCD to CCSD(T)/CCD.

$=-63.06$ and $\Delta E^{\mathrm{rep}}=+110.07 \mathrm{kcal} / \mathrm{mol}$. The $\Delta E^{\mathrm{pol}}$ is $-20.94 \mathrm{kcal} / \mathrm{mol}$, indicating that the Be orbitals change their shapes significantly in forming a dimer. As is well known, the main driving force for the formation of a Be dimer is the $\Delta E^{\text {disp }}$, which is $-9.45 \mathrm{kcal} / \mathrm{mol}$ as calculated with $\operatorname{CCSD}(\mathrm{T}) / \mathrm{ACC} 5(\mathrm{CP})$. The total interaction is $-1.94 \mathrm{kcal} /$ mol (Table IV), as compared to an experimental value of -2.14 to $-2.29 \mathrm{kcal} / \mathrm{mol}^{41}$ The main difference between the He dimer and Be dimer interactions is caused by the different static and dynamic polarizabilities of the $\mathrm{He} 1 s$ and $\mathrm{Be} 2 s$ orbitals.

\section{3. $\mathrm{CO}_{2} \cdots \mathrm{CO}_{2}$}

The MP2/ACCQ optimized $\mathrm{CO}_{2}$ dimer shows a parallel displaced shape with a parallel distance of $3.03 \AA$ and a displaced distance of $1.85 \AA$ (Fig. 3), similar to those obtained with the MP2/6-311+G(2df) by Tsuzuki et al. ${ }^{42}$ With $\Delta E^{\mathrm{ele}}=-1.76, \Delta E^{\mathrm{ex}}=-2.46, \Delta E^{\mathrm{rep}}=+4.31, \Delta E^{\mathrm{pol}}=-0.28$, and $\Delta E^{\text {disp }}=-1.19 \mathrm{kcal} / \mathrm{mol}$, the total MP2/ACCQ $(\mathrm{CP}) / / \mathrm{MP} 2 /$ ACCQ interaction energy is $-1.38 \mathrm{kcal} / \mathrm{mol}$ (Table IV and Table $\mathrm{S}^{32}$ ), very similar to $-1.33 \mathrm{kcal} / \mathrm{mol}$ obtained by Tsuzuki et al. ${ }^{42}$ Since the CCSD(T)/ACCT(CP) interaction energy is $0.07 \mathrm{kcal} / \mathrm{mol}$ more negative than the MP2/ $\mathrm{ACCT}(\mathrm{CP})$ value (Table $\mathrm{S} 4^{32}$ ), the $\mathrm{CCSD}(\mathrm{T}) / \mathrm{ACCQ}(\mathrm{CP})$ value can be estimated as $-1.45 \mathrm{kcal} / \mathrm{mol}$ (Table IV). Bukowski et al. ${ }^{43}$ performed SAPT calculations for $\mathrm{CO}_{2}$ dimer but a direct comparison between the SAPT and the current EDA interaction terms is difficult.

\section{4. $\mathrm{C}_{6} \mathrm{H}_{6} \cdots \mathrm{H}_{2} \mathrm{O}$ complex}

An MP2/ACCT optimization of benzene-water complex with no symmetry imposed led to a T-shaped geometry that is very close to a $C_{s}$ structure (Fig. 3). The distance between the center of mass of benzene and the water oxygen atom is $3.31 \AA$, comparable to an experimental value of $3.329 \AA .^{44}$ The total MP2/ACCQ(CP)//MP2/ACCT interaction energy is $-3.49 \mathrm{kcal} / \mathrm{mol}$, with $\Delta E^{\text {ele }}=-3.48, \Delta E^{\text {ex }}=-6.54, \Delta E^{\text {rep }}$ $=+11.02, \Delta E^{\mathrm{pol}}=-1.33$, and $\Delta E^{\mathrm{disp}}=-3.16 \mathrm{kcal} / \mathrm{mol}$ (Table IV and Table $S 4^{32}$ ). The results from $\operatorname{CCSD}(\mathrm{T}) / \mathrm{ACCD}(\mathrm{CP})$ and MP2/ACCD $(\mathrm{CP})$ suggest that MP2 overestimates the
$\Delta E^{\text {disp }}$ by $0.33 \mathrm{kcal} / \mathrm{mol}$ as compared to $\operatorname{CCSD}(\mathrm{T})$ (Table $\mathrm{S}^{32}{ }^{32}$. Therefore, the CCSD(T)/ACCQ(CP)//MP2/ACCT total interaction energy can be estimated as $-3.16 \mathrm{kcal} / \mathrm{mol}$ (Table IV), which is very close to a recently estimated CCSD(T)/CBS value of $-3.20 \mathrm{kcal} / \mathrm{mol}^{38}$

\section{5. $\mathrm{C}_{6} \mathrm{H}_{6}$ dimer}

The distorted T-shaped structure is among the most stable structures for benzene dimer. ${ }^{45}$ The distance between the center of mass in the two benzene molecules is $4.69 \AA$ in the MP2/ACCD optimized distorted T-shaped structure (Fig. 3). With $\Delta E^{\text {ele }}=-3.55, \Delta E^{\text {ex }}=-13.72, \Delta E^{\text {rep }}=+22.26, \Delta E^{\text {pol }}$ $=-1.26$, and $\Delta E^{\mathrm{disp}}=-7.27 \mathrm{kcal} / \mathrm{mol}$, the total MP2/ ACCT(CP)//MP2/ACCD interaction energy for the distorted T-shaped benzene dimer is $-3.53 \mathrm{kcal} / \mathrm{mol}$ (Table IV and Table $\mathrm{S}^{32}$ ). $\mathrm{CCSD}(\mathrm{T}) / \mathrm{CCD}$ and MP2/CCD results suggest that compared to $\operatorname{CCSD}(\mathrm{T})$, MP2 may overestimate the

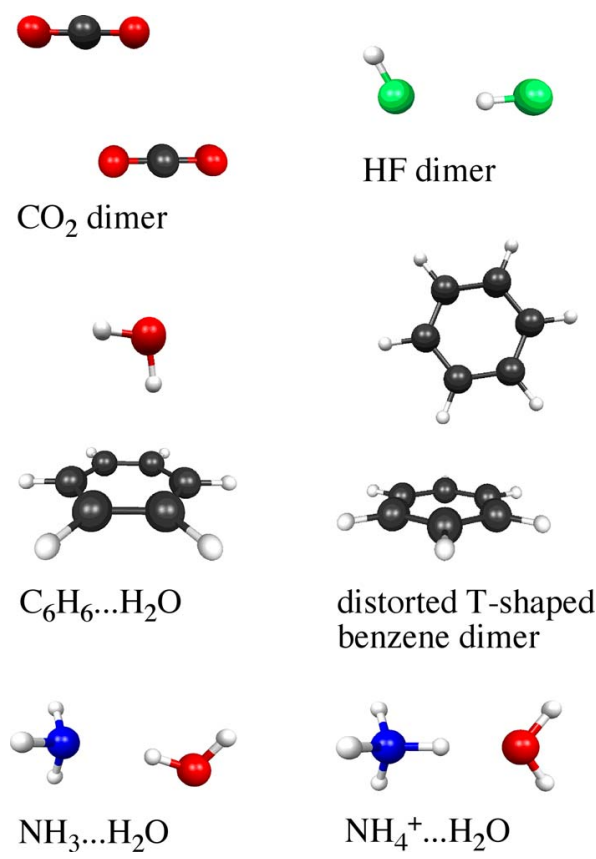

FIG. 3. Nonbonding complexes. 


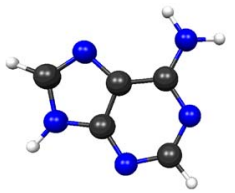

Adenine

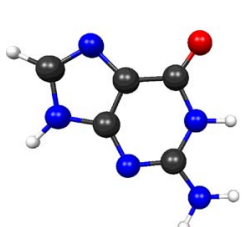

Guanine

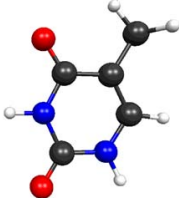

Thymine

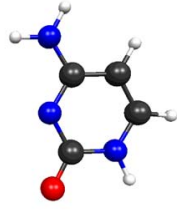

Cytosine
FIG. 4. MP2/ACCD optimized DNA base pairs.

$\Delta E^{\text {disp }}$ by $1.22 \mathrm{kcal} / \mathrm{mol}$ for this benzene dimer (Table $\mathrm{S} 4^{32}$ ). Therefore, the CCSD(T)/ACCT(CP) total interaction energy may be estimated as $-2.31 \mathrm{kcal} / \mathrm{mol}$ (Table IV), as compared to a recently estimated $\operatorname{CCSD}(\mathrm{T}) / \mathrm{CBS}$ value of $-2.84 \mathrm{kcal} / \mathrm{mol}^{38}$ The relatively large $\Delta E^{\text {ex }}$ and $\Delta E^{\text {rep }}$ $(-13.72$ and $+22.26 \mathrm{kcal} / \mathrm{mol}$, respectively) indicate that there is a significant orbital overlap between the two benzene molecules in the dimer. The overlap can also contribute to the $\Delta E^{\text {ele }}$ as a charge penetration effect. The very small $\Delta E^{\mathrm{pol}}$ suggests that the benzene orbitals undergo little changes in their shapes in the dimer formation process. As is well known, the main contribution in benzene dimer interaction is the dispersion energy.

\section{DNA base pairs}

The Watson-Crick structures of the adenine-thymine (AT) and guanine-cytosine (GC) pairs (Fig. 4) were optimized with the MP2/ACCD method in which only the spherical harmonic basis functions were used. The CCSD(T)/ CCD calculations were performed with only the spherical harmonic basis functions. The $\operatorname{CCSD}(\mathrm{T}) / \mathrm{CCD}$ dispersion energies are similar to the MP2/CCD ones: -5.91 vs $-6.12 \mathrm{kcal} / \mathrm{mol}$ for the AT pair and $-4.99 \mathrm{vs}-4.98 \mathrm{kcal} /$ mol for the GC pair, respectively (Table $\mathrm{S}^{32}$ ). Therefore, it is likely that $\operatorname{CCSD}(\mathrm{T})$ results will be similar to MP2 ones when larger basis sets are used. With $\Delta E^{\text {ele }}=-30.35$, $\Delta E^{\mathrm{ex}}=-40.21, \quad \Delta E^{\mathrm{rep}}=74.13, \quad \Delta E^{\mathrm{pol}}=-14.02, \quad$ and $\quad \Delta E^{\mathrm{disp}}$ $=-6.68 \mathrm{kcal} / \mathrm{mol}$, the total MP2 $/ \mathrm{ACCQ}(\mathrm{CP}) / / \mathrm{MP} 2 / \mathrm{ACCD}$ interaction energy for the AT pair is $-17.13 \mathrm{kcal} / \mathrm{mol}$ (Table IV and Table $\mathrm{S} 4^{32}$ ), as compared to $-16.6 \mathrm{kcal} / \mathrm{mol}$ obtained with resolution of the identity (RI)-MP2/ACCQ//RI-MP2/ CCT by Sponer $e t a l .{ }^{46}$ Considering the differences between the $\operatorname{CCSD}(\mathrm{T}) / \mathrm{CCD}$ and MP2/CCD results, the $\operatorname{CCSD}(\mathrm{T}) /$ ACCQ $(\mathrm{CP}) / / \mathrm{MP} 2 / \mathrm{ACCD}$ total interaction energy for the AT pair can be estimated as $-16.92 \mathrm{kcal} / \mathrm{mol}$ (Table IV). With $\Delta E^{\text {ele }}=-47.95$, $\Delta E^{\mathrm{ex}}=-52.95, \quad \Delta E^{\mathrm{rep}}=97.47, \quad \Delta E^{\mathrm{pol}}=-22.52, \quad$ and $\Delta E^{\mathrm{disp}}$ $=-6.16 \mathrm{kcal} / \mathrm{mol}$, the total MP2 $/ \mathrm{ACCQ}(\mathrm{CP}) / / \mathrm{MP} 2 / \mathrm{ACCD}$ interaction energy for the GC pair is $-32.11 \mathrm{kcal} / \mathrm{mol}$ (Table IV and Table $\mathrm{S}^{32}$ ), as compared to $-31.3 \mathrm{kcal} / \mathrm{mol}$ obtained with RI-MP2/ACCQ//RI-MP2/CCT. ${ }^{46}$ Considering the differences between the $\mathrm{CCSD}(\mathrm{T}) / \mathrm{CCD}$ and MP2/CCD results, the $\operatorname{CCSD}(\mathrm{T}) / \mathrm{ACCQ}(\mathrm{CP}) / / \mathrm{MP} 2 / \mathrm{ACCD}$ total interaction en- ergy for the GC pair can be estimated as $-32.12 \mathrm{kcal} / \mathrm{mol}$ (Table IV). The results of an ETS-NOCV energy decomposition calculation performed for the AT pair by Mitoraj et $a l .{ }^{15}$ are $\Delta E_{\text {elstat }}=-31.9, \Delta E_{\text {Pauli }}=+38.7$, and $\Delta E_{\text {orb }}=-22.0$, with $\Delta E_{\text {total }}=-15.2 \mathrm{kcal} / \mathrm{mol}$. These values are comparable to the EDA results obtained at the MP2/ACCQ(CP)//MP2/ ACCD level of theory: $\Delta E^{\mathrm{ele}}=-30.35, \Delta E^{\mathrm{ex}}+\Delta E^{\mathrm{rep}}=+33.92$, and $\Delta E^{\mathrm{pol}}+\Delta E^{\mathrm{disp}}=-20.70$, with $\Delta E_{\text {total }}=-17.13 \mathrm{kcal} / \mathrm{mol}$. In order to compare to experimentally measured enthalpy changes, preparation energy, zero point energy, and thermal energy are required. This is beyond the scope of the current paper. Experimental $\Delta H_{298} \mathrm{~K}$ values, -12.1 and $-21.0 \mathrm{kcal} /$ mol for Watson-Crick AT and GC pairs, respectively, and some discussions can be found in the literature. ${ }^{47}$

\section{7. $\mathrm{HF} \cdots \mathrm{HF}$}

The MP2/ACCQ optimized F-F distance is $2.744 \AA$ (Fig. 3). The EDA performed at the CCSD(T)/ACC5(CP) level of theory gives $\Delta E^{\text {ele }}=-6.76, \Delta E^{\text {ex }}=-5.71, \Delta E^{\text {rep }}$ $=+10.86, \Delta E^{\mathrm{pol}}=-2.23$, and $\Delta E^{\mathrm{disp}}=-0.72$ and a total interaction energy of $-4.56 \mathrm{kcal} / \mathrm{mol}$ (Table IV), which is close to $-4.49 \mathrm{kcal} / \mathrm{mol}$ obtained with $\operatorname{CCSD}(\mathrm{T}) / \operatorname{ACCQ}(\mathrm{CP}) / /$ MP2/ACCQ (only the pure harmonic sphere components were used) by Peterson and Dunning. ${ }^{48}$ The $\operatorname{CCSD}(\mathrm{T}) / \mathrm{CBS} / /$ MP2/ACCQ interaction energy could well be $-4.56 \mathrm{kcal} /$ mol. Clearly, all the hydrogen fluoride dimer interaction terms have slightly smaller magnitudes than the corresponding terms for the linear water dimer (Table II).

\section{8. $\mathrm{NH}_{3} \cdots \mathrm{H}_{2} \mathrm{O}$}

The MP2/ACCQ optimized $\mathrm{N}-\mathrm{O}$ distance in $\mathrm{NH}_{3} \cdots \mathrm{H}_{2} \mathrm{O}$ is $2.921 \AA$ (Fig. 3). The EDA performed at the $\operatorname{CCSD}(\mathrm{T}) / \mathrm{ACCQ}(\mathrm{CP})$ level of theory gives $\Delta E^{\text {ele }}=-11.88$, $\Delta E^{\mathrm{ex}}=-14.44, \Delta E^{\mathrm{rep}}=+25.95, \quad \Delta E^{\mathrm{pol}}=-4.07, \quad$ and $\Delta E^{\mathrm{disp}}$ $=-2.00$ and a total interaction energy of $-6.44 \mathrm{kcal} / \mathrm{mol}$ (Table IV), which is similar to an estimated CCSD(T)/CBS//MP2/6-311G** value of $-6.36 \mathrm{kcal} / \mathrm{mol}$ by Tsuzuki and Luthi. ${ }^{49}$ In general, the $\mathrm{NH}_{3} \cdot{ } \mathrm{H}_{2} \mathrm{O}$ complex shows a stronger interaction than water dimer and hydrogen fluoride dimer. The relative order of the hydrogen bond strength is $\mathrm{NH}_{3} \cdots \mathrm{H}_{2} \mathrm{O}>\left(\mathrm{H}_{2} \mathrm{O}\right)_{2}>(\mathrm{HF})_{2}$. This can be easily explained by the differences in their $\Delta E^{\text {ele }}$ terms, which show a reversed order: $-11.87<-8.41<-6.76$ (all in $\mathrm{kcal} / \mathrm{mol}$ ), as calculated from the HF/ACC5 electron densities.

\section{9. $\mathrm{NH}_{4}{ }^{+} \cdots \mathrm{H}_{2} \mathrm{O}$}

The MP2/ACCQ optimized $\mathrm{N}-\mathrm{O}$ distance in $\mathrm{NH}_{4}{ }^{+} \cdots \mathrm{H}_{2} \mathrm{O}$ is $2.698 \AA$ (Fig. 3). At the $\operatorname{CCSD}(\mathrm{T}) /$ ACCQ $(C P)$ level, EDA shows $\Delta E^{\text {ele }}=-25.38, \Delta E^{\text {ex }}=-18.56$, $\Delta E^{\mathrm{rep}}=+36.80, \Delta E^{\mathrm{pol}}=-11.80$, and $\Delta E^{\mathrm{disp}}=-1.86$ and a total interaction energy of $-20.79 \mathrm{kcal} / \mathrm{mol}$ (Table IV), which is close to an experimental value of $-20.6 \mathrm{kcal} / \mathrm{mol} .{ }^{50}$ Obviously, due to the positive charge on $\mathrm{NH}_{4}{ }^{+}$, the magnitudes of the interaction terms in $\mathrm{NH}_{4}{ }^{+} \cdots \mathrm{H}_{2} \mathrm{O}$ are all larger than those in $\mathrm{NH}_{3} \cdots \mathrm{H}_{2} \mathrm{O}$ except for the dispersion term. The large $\Delta E^{\text {pol }}$ in $\mathrm{NH}_{4}^{+} \cdots \mathrm{H}_{2} \mathrm{O}$ indicates that the $\mathrm{H}_{2} \mathrm{O}$ orbitals undergo significant changes in their shapes in order to maximize the strength of the hydrogen bond. 


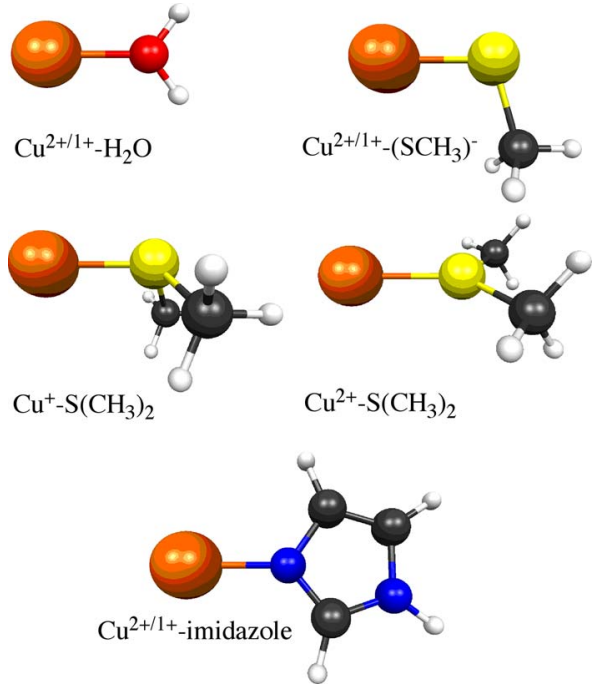

FIG. 5. MP2/ACCT optimized $\mathrm{Cu}^{2+/ 1+}$ complexes.

\section{E. Cu-ligand interaction}

Being an essential element, $\mathrm{Cu}$ plays an important role in living systems. The interaction energies between $\mathrm{Cu}$ ions and some biologically interesting ligands have been measured experimentally and calculated with quantum chemical methods. ${ }^{51}$ An interaction analysis with the RVS method was performed by Gresh et al. for some typical $\mathrm{Cu}^{+}$complexes, ${ }^{52}$ but a similar analysis has not been done for $\mathrm{Cu}^{2+}$ complexes. In this work the interactions in $\mathrm{Cu}-\mathrm{H}_{2} \mathrm{O}, \mathrm{Cu}$-imidazole, $\mathrm{Cu}-\left(\mathrm{SCH}_{3}\right)^{-}$, and $\mathrm{Cu}-\mathrm{S}\left(\mathrm{CH}_{3}\right)$ complexes (Fig. 5) are studied.

All the geometries were optimized with the MP2/ACCT method. EDA calculations were performed with CCSD, $\operatorname{CCSD}(\mathrm{T}), \mathrm{MP} 2, \mathrm{~B} 3 \mathrm{LYP}$, and BLYP methods based on the MP2/ACCT optimized geometries. In principle, the geometries should be optimized using the same method for the EDA calculations, especially when distinctively different methods such as MP2 and DFT are used (the basis set effects are usually not problematic in the ACCn series). A test on the $\mathrm{Cu}^{2+}-\mathrm{H}_{2} \mathrm{O}$ complex shows that the geometries optimized with the U-B3LYP/ACCT and UMP2/ACCT methods are similar, and the subsequent EDA calculations using the U-B3LYP/ACCT method show very similar total interaction energies (differ by $\sim 1 \mathrm{kcal} / \mathrm{mol}$, Table $\mathrm{S} 5^{32}$ ) with differences mainly in the Heitler-London term (i.e., $\Delta E^{\mathrm{ele}}+\Delta E^{\mathrm{ex}}$ $\left.+\Delta E^{\text {rep }}\right)$. The CP method was used to correct the BSSE, but approximately half of the cases did not converge either in the HF-SCF, DFT-SCF, or CCSD stage. Therefore, in Table V only the BSSE uncorrected data are presented for consistence and comparison. Using ACCQ, the BSSE corrected and uncorrected results are similar to within $0.5 \mathrm{kcal} / \mathrm{mol}$ for almost all the cases available for comparison. More data can be found in Table S5. ${ }^{32}$

The MP2/ACCT optimized $\mathrm{Cu}^{+}-\mathrm{H}_{2} \mathrm{O}$ and $\mathrm{Cu}^{2+}-\mathrm{H}_{2} \mathrm{O}$ complexes show similar planar $C_{2 v}$ geometries with $\mathrm{Cu}-\mathrm{O}$ distances of 1.918 and $1.820 \AA$, respectively (Fig. 5). With $\Delta E^{\mathrm{ele}}=-58.21, \Delta E^{\mathrm{ex}}=-41.25, \Delta E^{\mathrm{rep}}=89.67, \Delta E^{\mathrm{pol}}=-19.39$, and $\Delta E^{\text {disp }}=-9.97 \mathrm{kcal} / \mathrm{mol}$, the total CCSD $(\mathrm{T}) / \mathrm{ACCQ}$ interaction energy in $\mathrm{Cu}^{+}-\mathrm{H}_{2} \mathrm{O}$ is $-39.14 \mathrm{kcal} / \mathrm{mol}$ (Table V).
The relatively small $\Delta E^{\mathrm{pol}}$ and large $\Delta E^{\text {ele }}$ suggest that the $\mathrm{Cu}^{+}-\mathrm{H}_{2} \mathrm{O}$ interaction is mainly electrostatic. With $\Delta E^{\text {ele }}$ $=-96.46, \quad \Delta E^{\mathrm{ex}}=-40.29, \quad \Delta E^{\mathrm{rep}}=+104.16, \quad \Delta E^{\mathrm{pol}}=-63.89$, and $\Delta E^{\text {disp }}=-10.48 \mathrm{kcal} / \mathrm{mol}$, the total UMP2/ACCQ interaction energy in $\mathrm{Cu}^{2+}-\mathrm{H}_{2} \mathrm{O}$ is $-106.96 \mathrm{kcal} / \mathrm{mol}$ (Table $\mathrm{V}$ ), much larger than that in $\mathrm{Cu}^{+}-\mathrm{H}_{2} \mathrm{O}$. If only the depletion of an electron on going from $\mathrm{Cu}^{+}$to $\mathrm{Cu}^{2+}$ is considered, the magnitude of the $\Delta E^{\text {ex }}$ should decrease. However, a shorter distance in $\mathrm{Cu}^{2+}-\mathrm{H}_{2} \mathrm{O}$ brings the $\Delta E^{\text {ex }}$ back to $-40.29 \mathrm{kcal} /$ mol, similar to $-41.25 \mathrm{kcal} / \mathrm{mol}$ in $\mathrm{Cu}^{+}-\mathrm{H}_{2} \mathrm{O}$. The shorter distance in $\mathrm{Cu}^{2+}-\mathrm{H}_{2} \mathrm{O}$ also results in a sizable increase in the $\Delta E^{\text {rep }}$. The large $\Delta E^{\text {pol }}$ suggests that the $\mathrm{Cu}^{2+}-\mathrm{H}_{2} \mathrm{O}$ has a large covalency component. For $\mathrm{Cu}^{+}-\mathrm{H}_{2} \mathrm{O}$, MP2, B3LYP, and BLYP overestimate the total interaction energy by $\sim 1$, $\sim 2$, and $\sim 4 \mathrm{kcal} / \mathrm{mol}$ as compared to $\operatorname{CCSD}(\mathrm{T})$. For $\mathrm{Cu}^{2+}-\mathrm{H}_{2} \mathrm{O}$, RO-MP2, UMP2, U-B3LYP, and U-BLYP overestimate the total interaction energy by $\sim 0, \sim 0, \sim 11$, and $\sim 25 \mathrm{kcal} / \mathrm{mol}$ as compared to RO-CCSD (Table V). A $\operatorname{CCSD}(\mathrm{T})$ calculation $^{53}$ in the literature shows that the $\mathrm{Cu}^{2+}-\mathrm{H}_{2} \mathrm{O}$ distance is $1.841 \AA$, and the interaction energy is $-107.7 \mathrm{kcal} / \mathrm{mol}$, close to the CCSD result of -106.96 from this work. The main reason for the overestimation is the polarization energy, which is $-63.95 \mathrm{kcal} / \mathrm{mol}$ for ROMP2, $-63.89 \mathrm{kcal} / \mathrm{mol}$ for UMP2, $-82.81 \mathrm{kcal} / \mathrm{mol}$ for U-B3LYP, and $-105.59 \mathrm{kcal} / \mathrm{mol}$ for U-BLYP.

The MP2/ACCT optimized $\mathrm{Cu}^{+}$-imidazole and $\mathrm{Cu}^{2+}$-imidazole complexes show similar $C_{s}$ planar geometries with $\mathrm{Cu}-\mathrm{N}$ distances of 1.864 and $1.806 \AA$, respectively (Fig. 5). The total MP2/ACCQ interaction energy in $\mathrm{Cu}^{+}$-imidazole is $-73.92 \mathrm{kcal} / \mathrm{mol}$, with $\Delta E^{\mathrm{ele}}=-109.52$, $\Delta E^{\mathrm{ex}}=-72.39, \Delta E^{\mathrm{rep}}=+165.87, \Delta E^{\mathrm{pol}}=-35.62$, and $\Delta E^{\mathrm{disp}}$ $=-22.26 \mathrm{kcal} / \mathrm{mol}($ Table $\mathrm{V})$. The electrostatic energy has the largest contribution. In $\mathrm{Cu}^{2+}$-imidazole the total ROMP2/ ACCQ interaction energy is $-247.62 \mathrm{kcal} / \mathrm{mol}$, with $\Delta E^{\text {ele }}$ $=-117.25, \Delta E^{\mathrm{ex}}=-37.75, \Delta E^{\mathrm{rep}}=+97.22, \Delta E^{\mathrm{pol}}=-128.94$, and $\Delta E^{\text {disp }}=-60.99 \mathrm{kcal} / \mathrm{mol}$ (Table V). The electrostatic energy has the largest contribution, but polarization energy is also significant. Due to the large polarization energy, the coordinate bond of $\mathrm{Cu}^{2+}$-imidazole should be considered as a covalent bond. For $\mathrm{Cu}^{+}$-imidazole, MP2, B3LYP, and BLYP overestimate the interaction energy by $\sim 3, \sim 4$, and $\sim 9 \mathrm{kcal} / \mathrm{mol}$ as compared to $\operatorname{CCSD}(\mathrm{T})$. For $\mathrm{Cu}^{2+}$-imidazole, ROMP2, RO-B3LYP, and RO-BLYP overestimate the total interaction energy by $\sim 19, \sim 18$, and $\sim 34 \mathrm{kcal} / \mathrm{mol}$ as compared to the RO-CCSD method.

The MP2/ACCT optimized $\mathrm{Cu}^{+}-\left(\mathrm{SCH}_{3}\right)^{-}$and $\mathrm{Cu}^{2+}-\left(\mathrm{SCH}_{3}\right)^{-}$complexes show similar geometries with $\mathrm{Cu}-\mathrm{S}$ distances of 2.077 and $2.146 \AA$, respectively (Fig. 5). Though the $\mathrm{Cu}^{2+}-\mathrm{S}$ interaction is stronger, their distance is slightly longer. The total MP2/ACCQ interaction energy in $\mathrm{Cu}^{+}-\left(\mathrm{SCH}_{3}\right)^{-}$is $-195.17 \mathrm{kcal} / \mathrm{mol}$, with $\Delta E^{\mathrm{ele}}=-256.89$, $\Delta E^{\mathrm{ex}}=-98.09, \Delta E^{\mathrm{rep}}=+239.18, \Delta E^{\mathrm{pol}}=-45.61$, and $\Delta E^{\text {disp }}$ $=-33.77 \mathrm{kcal} / \mathrm{mol}$. The electrostatic energy makes the main contribution. The $\mathrm{Cu}^{+}-\left(\mathrm{SCH}_{3}\right)^{-}$bond is more covalent than that of $\mathrm{Cu}^{+}-\mathrm{H}_{2} \mathrm{O}$ but less covalent than the typical $\mathrm{BH}_{3}-\mathrm{CO}$ and $\mathrm{BH}_{3}-\mathrm{NH}_{3}$ coordinate bonds (Table I). The total UMP2/ ACCQ energy in $\mathrm{Cu}^{2+}-\left(\mathrm{SCH}_{3}\right)^{-}$is $-493.29 \mathrm{kcal} / \mathrm{mol}$, with $\Delta E^{\mathrm{ele}}=-371.97, \quad \Delta E^{\mathrm{ex}}=-64.28, \quad \Delta E^{\mathrm{rep}}=+181.18, \quad \Delta E^{\mathrm{pol}}$ $=-158.94$, and $\Delta E^{\mathrm{disp}}=-79.28 \mathrm{kcal} / \mathrm{mol}$. The magnitudes of 
TABLE V. Cu-ligand interaction ( $\mathrm{kcal} / \mathrm{mol})$.

\begin{tabular}{|c|c|c|c|c|c|c|c|}
\hline Molecule & Level of theory & $\Delta E^{\text {ele }}$ & $\Delta E^{\mathrm{ex}}$ & $\Delta E^{\mathrm{rep}}$ & $\Delta E^{\mathrm{pol}}$ & $\Delta E^{\mathrm{disp}}$ & $\Delta E$ \\
\hline \multirow[t]{4}{*}{$\mathrm{Cu}^{+}-\mathrm{H}_{2} \mathrm{O}$} & $\mathrm{CCSD}(\mathrm{T}) / \mathrm{ACCQ} / / \mathrm{MP} 2 / \mathrm{ACCT}$ & -58.21 & -41.25 & 89.67 & -19.39 & -9.97 & -39.14 \\
\hline & MP2/ACCQ//MP2/ACCT & -58.21 & -41.25 & 89.67 & -19.39 & -11.00 & -40.18 \\
\hline & B3LYP/ACCQ//MP2/ACCT & -61.14 & -23.68 & 79.68 & -29.25 & -6.84 & -41.23 \\
\hline & BLYP/ACCQ//MP2/ACCT & -62.17 & -17.26 & 77.08 & -32.95 & -7.89 & -43.19 \\
\hline \multirow[t]{5}{*}{$\mathrm{Cu}^{+}$-imidazole } & $\operatorname{CCSD}(\mathrm{T}) / \mathrm{ACCT} / / \mathrm{MP} 2 / \mathrm{ACCT}$ & -109.97 & -72.67 & 166.68 & -35.82 & -19.05 & -70.83 \\
\hline & MP2/ACCT//MP2/ACCT & -109.97 & -72.67 & 166.68 & -35.82 & -21.98 & -73.76 \\
\hline & MP2/ACCQ//MP2/ACCT & -109.52 & -72.39 & 165.87 & -35.62 & -22.26 & -73.92 \\
\hline & B3LYP/ACCQ//MP2/ACCT & -114.08 & -41.50 & 141.77 & -52.48 & -8.13 & -74.42 \\
\hline & BLYP/ACCQ//MP2/ACCT & -116.03 & -31.60 & 136.25 & -58.81 & -9.33 & -79.53 \\
\hline \multirow[t]{4}{*}{$\mathrm{Cu}^{+}-\left(\mathrm{SCH}_{3}\right)^{-}$} & $\operatorname{CCSD}(\mathrm{T}) / \mathrm{ACCQ} / / \mathrm{MP} 2 / \mathrm{ACCT}$ & -256.89 & -98.09 & 239.18 & -45.61 & -30.11 & -191.51 \\
\hline & MP2/ACCQ//MP2/ACCT & -256.89 & -98.09 & 239.18 & -45.61 & -33.77 & -195.17 \\
\hline & B3LYP/ACCQ//MP2/ACCT & -257.43 & -58.67 & 199.78 & -71.43 & -10.78 & -198.52 \\
\hline & BLYP/ACCQ//MP2/ACCT & -257.96 & -46.95 & 190.97 & -81.21 & -12.27 & -207.41 \\
\hline \multirow[t]{5}{*}{$\mathrm{Cu}^{+}-\mathrm{S}\left(\mathrm{CH}_{3}\right)_{2}$} & $\operatorname{CCSD}(\mathrm{T}) / \mathrm{ACCT} / \mathrm{MP} 2 / \mathrm{ACCT}$ & -89.77 & -66.54 & 156.27 & -35.30 & -20.73 & -56.08 \\
\hline & MP2/ACCT//MP2/ACCT & -89.77 & -66.54 & 156.27 & -35.30 & -23.92 & -59.26 \\
\hline & MP2/ACCQ//MP2/ACCT & -89.34 & -66.35 & 155.61 & -35.20 & -24.42 & -59.70 \\
\hline & B3LYP/ACCQ//MP2/ACCT & -89.44 & -38.62 & 129.25 & -54.62 & -8.20 & -61.62 \\
\hline & BLYP/ACCQ//MP2/ACCT & -90.87 & -30.15 & 124.22 & -62.00 & -9.46 & -68.26 \\
\hline \multirow[t]{5}{*}{$\mathrm{Cu}^{2+}-\mathrm{H}_{2} \mathrm{O}$} & RO-CCSD/ACCT//UMP2/ACCT & -96.58 & -40.33 & 104.51 & -63.95 & -10.43 & -106.78 \\
\hline & ROMP2/ACCT//UMP2/ACCT & -96.58 & -40.33 & 104.51 & -63.95 & -10.04 & -106.40 \\
\hline & UMP2/ACCQ//UMP2/ACCT & -96.46 & -40.29 & 104.16 & -63.89 & -10.48 & -106.96 \\
\hline & U-B3LYP/ACCQ//UMP2/ACCT & -94.46 & -21.90 & 91.81 & -82.81 & -10.35 & -117.70 \\
\hline & U-BLYP/ACCQ//UMP2/ACCT & -87.62 & -14.95 & 89.18 & -105.59 & -12.74 & -131.71 \\
\hline \multirow[t]{5}{*}{$\mathrm{Cu}^{2+}$-imidazole } & RO-CCSD/ACCD-T $\mathrm{a} / / \mathrm{ROMP} 2 / \mathrm{ACCT}$ & -118.94 & -37.88 & 97.74 & -127.69 & -47.58 & -234.35 \\
\hline & ROMP2/ACCD-Ta//ROMP2/ACCT & -118.94 & -37.88 & 97.74 & -127.69 & -66.64 & -253.41 \\
\hline & ROMP2/ACCQ//ROMP2/ACCT & -117.25 & -37.75 & 97.22 & -128.94 & -60.99 & -247.62 \\
\hline & RO-B3LYP/ACCQ//ROMP2/ACCT & -117.59 & -21.56 & 85.17 & -180.31 & -12.42 & -246.72 \\
\hline & RO-BLYP/ACCQ//ROMP2/ACCT & -93.16 & -34.28 & 81.35 & -203.26 & -13.20 & -262.54 \\
\hline \multirow[t]{6}{*}{$\mathrm{Cu}^{2+}-\left(\mathrm{SCH}_{3}\right)^{-}$} & RO-CCSD/ACCD-T $/ /$UMP2/ACCT & -375.94 & -66.69 & 187.42 & -156.79 & -61.53 & -473.53 \\
\hline & ROMP2/ACCD-T $/ /$ UMP2/ACCT & -375.94 & -66.69 & 187.42 & -156.79 & -87.65 & -499.65 \\
\hline & UMP2/ACCD-T'//UMP2/ACCT & -375.40 & -64.72 & 184.30 & -157.31 & -84.46 & -497.59 \\
\hline & UMP2/ACCQ//UMP2/ACCT & -371.97 & -64.28 & 181.18 & -158.94 & -79.28 & -493.29 \\
\hline & U-B3LYP/ACCQ//UMP2/ACCT & -366.99 & -39.36 & 155.99 & -227.39 & -16.43 & -494.18 \\
\hline & U-BLYP/ACCQ//UMP2/ACCT & -353.56 & -30.96 & 142.55 & -254.59 & -17.87 & -514.43 \\
\hline \multirow[t]{6}{*}{$\mathrm{Cu}^{2+}-\mathrm{S}\left(\mathrm{CH}_{3}\right)_{2}$} & RO-CCSD/ACCD-T $/ /$ UMP2/ACCT & -57.84 & -20.54 & 54.20 & -119.27 & -52.49 & -195.92 \\
\hline & ROMP2/ACCD-T $/ / \mathrm{UMP} 2 / \mathrm{ACCT}$ & -57.84 & -20.54 & 54.20 & -119.27 & -77.61 & -221.04 \\
\hline & UMP2/ACCD-T'//UMP2/ACCT & -57.83 & -20.53 & 54.19 & -120.61 & -74.16 & -218.94 \\
\hline & UMP2/ACCQ//UMP2/ACCT & -57.16 & -19.90 & 52.57 & -120.93 & -69.49 & -214.90 \\
\hline & U-B3LYP/ACCQ//UMP2/ACCT & -53.34 & -11.69 & 46.58 & -187.50 & -11.22 & -217.18 \\
\hline & U-BLYP/ACCQ//UMP2/ACCT & -45.36 & -10.78 & 44.91 & -212.90 & -12.39 & -236.53 \\
\hline
\end{tabular}

${ }^{\mathrm{a}}$ Mixed basis set: ACCT for $\mathrm{Cu}, \mathrm{ACCD}$ for the three $\mathrm{C}, \mathrm{N}$, and $\mathrm{C}$ atoms closest to $\mathrm{Cu}$, and $\mathrm{CCD}$ for other atoms.

${ }^{\mathrm{b}}$ Mixed basis set: ACCT for $\mathrm{Cu}$ and ACCD for other atoms.

the exchange and repulsion energies in $\mathrm{Cu}^{2+}-\left(\mathrm{SCH}_{3}\right)^{-}$are $\sim 2 / 3$ of those in $\mathrm{Cu}^{+}-\mathrm{SCH}_{3}^{-}$due to the increase in the $\mathrm{Cu}-\mathrm{S}$ distance and the loss of an electron. It is well known that $\mathrm{Cu}^{2+}$-thiolate bond is highly covalent. ${ }^{54}$ The large polarization energy from EDA is in accord with the established picture. For $\mathrm{Cu}^{+}-\left(\mathrm{SCH}_{3}\right)^{-}, \mathrm{MP} 2, \mathrm{~B} 3 \mathrm{LYP}$, and BLYP overestimate the total interaction energy by $\sim 4, \sim 7$, and $\sim 16 \mathrm{kcal} / \mathrm{mol}$ as compared to $\operatorname{CCSD}(\mathrm{T})$. For $\mathrm{Cu}^{2+}-\left(\mathrm{SCH}_{3}\right)^{-}$, UMP2, U-B3LYP, and U-BLYP overestimate the interaction energy by $\sim 24, \sim 25$, and $\sim 45 \mathrm{kcal} / \mathrm{mol}$ as compared to RO-CCSD.

$\mathrm{Cu}^{+}-\mathrm{S}\left(\mathrm{CH}_{3}\right)_{2}$ and $\mathrm{Cu}^{2+}-\mathrm{S}\left(\mathrm{CH}_{3}\right)_{2}$ show completely different structures (Fig. 5). Although $\mathrm{Cu}^{2+}$ has a stronger interaction with $\mathrm{S}\left(\mathrm{CH}_{3}\right)_{2}$, the $\mathrm{Cu}^{2+}-\mathrm{S}$ distance, $2.341 \AA$, is actually longer than the $\mathrm{Cu}^{+}-\mathrm{S}$ distance of $2.159 \AA$. For $\mathrm{Cu}^{+}-\mathrm{S}\left(\mathrm{CH}_{3}\right)_{2}$, the MP2/ACCQ total interaction energy is
$-59.70 \mathrm{kcal} / \mathrm{mol}$, with $\Delta E^{\mathrm{ele}}=-89.34, \Delta E^{\mathrm{ex}}=-66.35, \Delta E^{\mathrm{rep}}$ $=+155.61, \Delta E^{\mathrm{pol}}=-35.20$, and $\Delta E^{\mathrm{disp}}=-24.42 \mathrm{kcal} / \mathrm{mol}$. For $\mathrm{Cu}^{2+}-\mathrm{S}\left(\mathrm{CH}_{3}\right)_{2}$, the UMP2/ACCQ total interaction energy is $-214.90 \mathrm{kcal} / \mathrm{mol}$, with $\Delta E^{\text {ele }}=-57.16, \Delta E^{\text {ex }}$ $=-19.90, \Delta E^{\mathrm{rep}}=+52.57, \quad \Delta E^{\mathrm{pol}}=-120.93, \quad$ and $\Delta E^{\mathrm{disp}}$ $=-69.49 \mathrm{kcal} / \mathrm{mol}$. Clearly, the $\mathrm{Cu}^{+}-\mathrm{S}\left(\mathrm{CH}_{3}\right)_{2}$ interaction is dominated by electrostatic, while the $\mathrm{Cu}^{2+}-\mathrm{S}\left(\mathrm{CH}_{3}\right)_{2}$ interaction is dominated by polarization, like a covalent bond. For $\mathrm{Cu}^{+}-\mathrm{S}\left(\mathrm{CH}_{3}\right)_{2}, \mathrm{MP} 2$, B3LYP, and BLYP overestimate the total interaction energy by $\sim 3, \sim 5$, and $\sim 12 \mathrm{kcal} / \mathrm{mol}$ as compared to $\mathrm{CCSD}(\mathrm{T})$. For $\mathrm{Cu}^{2+}-\mathrm{S}\left(\mathrm{CH}_{3}\right)_{2}, \quad \mathrm{UMP} 2$, U-B3LYP, and U-BLYP overestimate the interaction energy by $\sim 23, \sim 25$, and $\sim 45 \mathrm{kcal} / \mathrm{mol}$ as compared to the ROCCSD method.

To summarize, the negatively charged thiolate $\left(\mathrm{SCH}_{3}\right)^{-}$ forms the strongest bond to $\mathrm{Cu}^{2+/ 1+}$. The neutral ligands imi- 
TABLE VI. Ionic interaction ( $\mathrm{kcal} / \mathrm{mol})$.

\begin{tabular}{|c|c|c|c|c|c|c|c|}
\hline Molecule & Level of theory & $\Delta E^{\text {ele }}$ & $\Delta E^{\mathrm{ex}}$ & $\Delta E^{\text {rep }}$ & $\Delta E^{\mathrm{pol}}$ & $\Delta E^{\mathrm{disp}}$ & $\Delta E$ \\
\hline $\mathrm{Li}^{+} \mathrm{F}^{-}$ & $\operatorname{CCSD}(\mathrm{T}) / \mathrm{ACC} 5(\mathrm{CP}) / / \mathrm{MP} 2 / \mathrm{ACCQ}$ & -206.29 & -21.71 & 63.39 & -21.98 & +2.34 & -184.25 \\
\hline $\mathrm{Li}^{+} \mathrm{Cl}^{-}$ & $\operatorname{CCSD}(\mathrm{T}) / \mathrm{ACC} 5(\mathrm{CP}) / / \mathrm{MP} 2 / \mathrm{ACCQ}$ & -157.97 & -15.43 & 46.85 & -25.82 & -1.29 & -153.66 \\
\hline $\mathrm{Na}^{+} \mathrm{F}^{-}$ & $\operatorname{CCSD}(\mathrm{T}) / \mathrm{ACC} 5(\mathrm{CP}) / / \mathrm{MP} 2 / \mathrm{ACCQ}$ & -176.30 & -21.40 & 52.61 & -9.06 & +0.66 & -153.49 \\
\hline $\mathrm{Na}^{+} \mathrm{Cl}^{-}$ & $\operatorname{CCSD}(\mathrm{T}) / \mathrm{ACC} 5(\mathrm{CP}) / / \mathrm{MP} 2 / \mathrm{ACCQ}$ & -143.89 & -17.99 & 45.14 & -12.92 & -2.21 & -131.87 \\
\hline
\end{tabular}

dazole and $\mathrm{S}\left(\mathrm{CH}_{3}\right)$ form much weaker coordinate bonds to $\mathrm{Cu}^{2+/ 1+}$. Water forms the weakest coordinate bond to $\mathrm{Cu}^{2+/ 1+}$. $\mathrm{Cu}^{+}$-ligand interactions are mainly electrostatic, while $\mathrm{Cu}^{2+}$-ligand interactions are much more covalent. MP2, B3LYP, and BLYP can predict reasonably good binding energies for $\mathrm{Cu}^{+}$complexes.

\section{F. lonic bonding}

There is no doubt that electron correlation methods such as MP2 and $\operatorname{CCSD(T)~will~give~a~lower~total~energy~as~com-~}$ pared to HF methods for any molecular system with more than one electron. For intermolecular interactions, however, electron correlation methods do not necessarily predict stronger interaction energies than HF methods, as have been documented, for example, by Sannigrahi et al. in a quantum chemical study of alkali halides. ${ }^{55}$ Here the results of EDA calculations for $\mathrm{Li}^{+} \mathrm{F}^{-}, \mathrm{Li}^{+} \mathrm{Cl}^{-}, \mathrm{Na}^{+} \mathrm{F}^{-}$, and $\mathrm{Na}^{+} \mathrm{Cl}^{-}$are reported. Because $\mathrm{Li}^{+}$and $\mathrm{Na}^{+}$ions have no valence electrons, the MP2 and $\operatorname{CCSD}(\mathrm{T})$ calculations discussed below were performed with full excitation (no frozen core).

The MP2/ACCQ optimized bond lengths of $\mathrm{Li}^{+} \mathrm{F}^{-}$, $\mathrm{Li}^{+} \mathrm{Cl}^{-}, \mathrm{Na}^{+} \mathrm{F}^{-}$, and $\mathrm{Na}^{+} \mathrm{Cl}^{-}$are $1.574,2.023,1.949$, and $2.380 \AA$, respectively, compared well to the experimental values of $1.564,2.021,1.926$, and $2.361 \AA^{27}$ The total CCSD(T)/ACC5(CP)//MP2/ACCQ interaction energies of these four ionic complexes are $-184.25,-153.66,-153.49$, and $-131.87 \mathrm{kcal} / \mathrm{mol}$, respectively (Table VI), in excellent agreement with the experimental values of $-183.5 \pm 2.2$, $-154.0 \pm 0.1,-153.3 \pm 0.9$, and $-132.4 \pm 0.8 \mathrm{kcal} / \mathrm{mol} .{ }^{56}$ Clearly, the ions form strong ionic bonds as indicated by the $\Delta E^{\text {ele }}$ values of $-206.29,-157.97,-176.30$, and -143.88 $\mathrm{kcal} / \mathrm{mol}$. The relatively small polarization energies are mainly from the anions $\mathrm{F}^{-}$and $\mathrm{Cl}^{-}$as the $\mathrm{Li}^{+}$and $\mathrm{Na}^{+}$cations are typical hard ions. As expected, $\mathrm{Li}^{+} \mathrm{Cl}^{-}$shows the largest polarization energy of $-25.82 \mathrm{kcal} / \mathrm{mol}$, while $\mathrm{Na}^{+} \mathrm{F}^{-}$shows the smallest polarization energy of $-9.06 \mathrm{kcal} / \mathrm{mol}$ (Table VI). The $\Delta E^{\text {ex }}$ and $E^{\text {rep }}$ are similar in all of these ion pairs.

It is interesting that the $\mathrm{CCSD}(\mathrm{T}) / \mathrm{ACC} 5(\mathrm{CP})$ dispersion energies in $\mathrm{Li}^{+} \mathrm{F}^{-}$and $\mathrm{Na}^{+} \mathrm{F}^{-}$are positive (repulsive): +2.34 and $+0.66 \mathrm{kcal} / \mathrm{mol}$, respectively. Similar values can be found in an earlier work that used HF and MP2 methods. ${ }^{55}$ This is caused by the differences in the intra- and interionic correlation energy on going from noninteracting to interacting ions and can be basis set and distance sensitive (Table $\mathrm{S}^{32}$ ). It is obvious that at the $\operatorname{CBS}$ limit, $\operatorname{CCSD}(\mathrm{T})$ will predict a positive dispersion energy for $\mathrm{Li}^{+} \mathrm{F}^{-}$, but the sign for $\mathrm{Na}^{+} \mathrm{F}^{-}$is not clear. A plot of the $\Delta E^{\text {disp }}$ obtained with $\operatorname{CCSD}(\mathrm{T}) / \mathrm{ACCQ}(\mathrm{CP})$ for $\mathrm{Li}^{+} \mathrm{F}^{-}$at different separation distances shows that the $\Delta E^{\text {disp }}$ will turn into negative (attractive) at $2.09 \AA$ (Fig. 6).

\section{CONCLUSION}

An EDA method was implemented in GAMESS to perform interaction analysis for both bonding and nonbonding interactions on the basis of RHF, ROHF, UHF, R-KS, ROKS, and U-KS wavefunctions. For HF methods, MP2, $\mathrm{CCSD}$, and $\operatorname{CCSD}(\mathrm{T})$ are used to evaluate the dispersion energy. To conclude, the following points are highlighted:

(1) This EDA is basis set insensitive because no chargetransfer term or assignment of electron density to monomers is involved. The interaction terms show convergence as the basis set approaches the CBS limit. For most of the tested cases, the ACCT basis set converges the HF and DFT interaction terms, and the ACCQ basis set with BSSE correction converges the MP2, CCSD, and $\operatorname{CCSD}(\mathrm{T})$ dispersion terms, respectively, to within $1.0 \mathrm{kcal} / \mathrm{mol}$ of the CBS limit (see the data in supplementary tables).

(2) Covalent bonds are characterized by large polarization energies, typically $-100 \mathrm{kcal} / \mathrm{mol}$, as the results of significant orbital deformations. B3LYP and BLYP methods can predict bond energies that are comparable to those from the CCSD method for some typical covalent bonds such as $\mathrm{H}-\mathrm{H}, \mathrm{C}-\mathrm{H}$, and $\mathrm{C}-\mathrm{C}$ (Table I), but the errors for coordinate covalent bonds are substantially large (Tables I and V).

(3) The results for staggered and eclipsed ethane clearly indicate that the exchange-repulsion energy is the main cause of the $\sim 3 \mathrm{kcal} / \mathrm{mol}$ rotation barrier (Table I).

(4) For water tetramer, many-body polarization is $-6.64 \mathrm{kcal} / \mathrm{mol}$, many-body repulsion is $-0.41 \mathrm{kcal} /$ $\mathrm{mol}$, and many-body dispersion is $-0.08 \mathrm{kcal} / \mathrm{mol}$, as computed with the MP2/ACC5 method (Table III).

(5) The interaction energies for two DNA base pairs, AT and $\mathrm{GC}$, are obtained as -17.13 and $-32.11 \mathrm{kcal} / \mathrm{mol}$

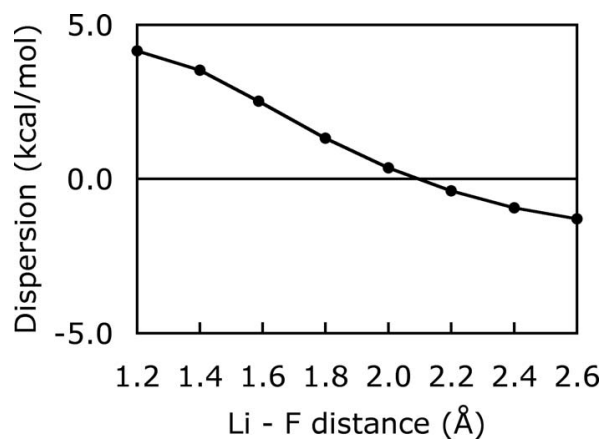

FIG. 6. Positive dispersion interaction between $\mathrm{Li}^{+}$and $\mathrm{F}^{-}$calculated with $\operatorname{CCSD}(\mathrm{T}) / \mathrm{ACCQ}(\mathrm{CP})$. The experimental $\mathrm{Li}-\mathrm{F}$ equilibrium distance is $1.564 \AA$. 
at the MP2/ACCQ(CP)//MP2/ACCD levels of theory (Table IV).

(6) $\mathrm{Cu}^{+}-\mathrm{H}_{2} \mathrm{O}, \mathrm{Cu}^{+}$-imidazole, $\mathrm{Cu}^{+}-\left(\mathrm{SCH}_{3}\right)^{-}, \quad$ and $\mathrm{Cu}^{+}-\mathrm{S}\left(\mathrm{CH}_{3}\right)_{2}$ interactions are mainly electrostatic, while $\mathrm{Cu}^{2+}-\mathrm{H}_{2} \mathrm{O}, \mathrm{Cu}^{2+}$-imidazole, $\mathrm{Cu}^{2+}-\left(\mathrm{SCH}_{3}\right)^{-}$, and $\mathrm{Cu}^{2+}-\mathrm{S}\left(\mathrm{CH}_{3}\right)_{2}$ interactions are covalent. Compared to CCSD, MP2, B3LYP, and BLYP tend to overestimate $\mathrm{Cu}$-ligand interactions, especially for $\mathrm{Cu}^{2+}$ complexes (Table V).

(7) $\mathrm{For}^{\mathrm{L}} \mathrm{F}^{+}, \mathrm{CCSD}(\mathrm{T})$ predicts smaller interaction energy than the HF method (Table VI).

\section{ACKNOWLEDGMENTS}

This work was supported by startup funds from the University of Nebraska-Lincoln. The authors are grateful to Michael W. Schmidt for his critical comments on the manuscript.

${ }^{1}$ A. J. Stone, The Theory of Intermolecular Forces (Oxford University Press, New York, 1996).

${ }^{2}$ K. Szalewicz and B. Jeziorski, Mol. Phys. 38, 191 (1979); B. Jeziorski, R. Moszynski, and K. Szalewicz, Chem. Rev. (Washington, D.C.) 94, 1887 (1994).

${ }^{3}$ A. J. Misquitta, R. Podeszwa, B. Jeziorski, and K. Szalewicz, J. Chem. Phys. 123, 214103 (2005); H. L. Williams and C. F. Chabalowski, J. Phys. Chem. A 105, 646 (2001); G. Jansen and A. Hesselmann, ibid. 105, 11156 (2001); A. Heßelmann and G. Jansen, Chem. Phys. Lett. 357, 464 (2002).

${ }^{4}$ G. Chalasinski and M. M. Szczesniak, Mol. Phys. 63, 205 (1988).

${ }^{5}$ V. F. Lotrich and K. Szalewicz, J. Chem. Phys. 106, 9688 (1997); V. F. Lotrich, P. Jankowski, and K. Szalewicz, ibid. 108, 4725 (1998).

${ }^{6}$ K. Morokuma, J. Chem. Phys. 55, 1236 (1971); K. Morokuma and K. Kitaura, in Chemical Applications of Atomic and Molecular Electronic Potentials, edited by P. Politzer and D. G. Truhlar (Plenum, New York, 1981), p. 215.

${ }^{7}$ K. Kitaura and K. Morokuma, Int. J. Quantum Chem. 10, 325 (1976).

${ }^{8}$ W. Chen and M. S. Gordon, J. Phys. Chem. 100, 14316 (1996).

${ }^{9}$ E. D. Glendening and A. Streitwieser, J. Chem. Phys. 100, 2900 (1994).

${ }^{10}$ P. S. Bagus, K. Hermann, and J. C. W. Bauschlicher, J. Chem. Phys. 80, 4378 (1984); P. S. Bagus and F. Illas, ibid. 96, 8962 (1992).

${ }^{11}$ W. J. Stevens and W. H. Fink, Chem. Phys. Lett. 139, 15 (1987).

${ }^{12}$ Y. R. Mo, J. L. Gao, and S. D. Peyerimhoff, J. Chem. Phys. 112, 5530 (2000).

${ }^{13}$ R. Z. Khaliullin, E. A. Cobar, R. C. Lochan, A. T. Bell, and M. HeadGordon, J. Phys. Chem. A 111, 8753 (2007).

${ }^{14}$ T. Ziegler and A. Rauk, Theor. Chem. Acc. 46, 1 (1977); G. T. te Velde, F. M. Bickelhaupt, E. J. Baerends, C. F. Guerra, S. J. A. Van Gisbergen, J. G. Snijders, and T. Ziegler, J. Comput. Chem. 22, 931 (2001); F. M. Bickelhaupt and E. J. Baerends, Reviews in Computational Chemistry (Wiley-VCH, New York, 2000), Vol. 15, p. 1.

${ }^{15}$ M. P. Mitoraj, A. Michalak, and T. Ziegler, J. Comput. Chem. 5, 962 (2009).

${ }^{16}$ E. D. Glendening, J. Phys. Chem. A 109, 11936 (2005); P. Reinhardt, J. P. Piquemal, and A. Savin, J. Chem. Theory Comput. 4, 2020 (2008).

${ }^{17}$ T. Ziegler and A. Rauk, Inorg. Chem. 18, 1755 (1979).

${ }^{18}$ I. C. Hayes and A. J. Stone, Mol. Phys. 53, 83 (1984).

${ }^{19}$ M. W. Schmidt, K. K. Baldridge, J. A. Boatz, S. T. Elbert, M. S. Gordon, J. H. Jensen, S. Koseki, N. Matsunaga, K. A. Nguyen, S. J. Su, T. L. Windus, M. Dupuis, and J. A. Montgomery, J. Comput. Chem. 14, 1347 (1993); M. S. Gordon and M. W. Schmidt, in Theory and Applications of Computational Chemistry, edited by C. E. Dykstra, G. Frenking, K. S. Kim, and G. E. Scuseria (Elsevier, Amsterdam, 2005).

${ }^{20}$ J. A. P. J. S. Binkley, Int. J. Quantum Chem. 9, 229 (1975); M. J. Frisch, M. Head-Gordon, and J. A. Pople, Chem. Phys. Lett. 166, 275 (1990); C. M. Aikens, S. P. Webb, R. L. Bell, G. D. Fletcher, M. W. Schmidt, and M S. Gordon, Theor. Chem. Acc. 110, 233 (2003).

${ }^{21}$ P. Piecuch, S. A. Kucharski, K. Kowalski, and M. Musial, Comput. Phys. Commun. 149, 71 (2002); J. L. Bentz, R. M. Olson, M. S. Gordon, M.
W. Schmidt, and R. A. Kendall, ibid. 176, 589 (2007); R. M. Olson, J. L. Bentz, R. A. Kendall, M. W. Schmidt, and M. S. Gordon, J. Chem. Theory Comput. 3, 1312 (2007); P. Piecuch and M. Wloch, J. Chem. Phys. 123, 224105 (2005); M. Wloch, J. R. Gour, and P. Piecuch, J. Phys. Chem. A 111, 11359 (2007).

${ }^{22}$ G. D. Fletcher, M. W. Schmidt, B. M. Bode, and M. S. Gordon, Comput. Phys. Commun. 128, 190 (2000).

${ }^{23}$ S. F. Boys and F. Bernardi, Mol. Phys. 19, 553 (1970).

${ }^{24}$ T. H. Dunning, J. Chem. Phys. 90, 1007 (1989); N. B. Balabanov and K. A. Peterson, ibid. 123, 064107 (2005).

${ }^{25}$ R. H. Hertwig and W. Koch, Chem. Phys. Lett. 268, 345 (1997).

${ }^{26}$ A. D. Becke, Phys. Rev. A 38, 3098 (1988); C. Lee, W. Yang, and R. G. Parr, Phys. Rev. B 37, 785 (1988).

${ }^{27}$ K. P. Huber and G. Herzberg, Molecular Spectra and Molecular Structure IV. Constants of Diatomic Molecules (Van Nostrand Reinhold, New York, 1979).

${ }^{28}$ Z. X. Tian, A. Fattahi, L. Lis, and S. R. Kass, J. Am. Chem. Soc. 128, 17087 (2006).

${ }^{29}$ V. Jonas, G. Frenking, and M. T. Reetz, J. Am. Chem. Soc. 116, 8741 (1994); K. Morokuma, Acc. Chem. Res. 10, 294 (1977); Y. R. Mo, L. C. Song, W. Wu, and Q. N. Zhang, J. Am. Chem. Soc. 126, 3974 (2004).

${ }^{30}$ A. C. Venkatachar, R. C. Taylor, and R. L. Kuczkowski, J. Mol. Struct. 38, 17 (1977)

${ }^{31}$ L. R. Thorne, R. D. Suenram, and F. J. Lovas, J. Chem. Phys. 78, 167 (1983).

${ }^{32}$ See EPAPS Document No. http://dx.doi.org/10.1063/1.3159673 for Tables S1-S6.

${ }^{33}$ S. Weiss and G. E. Leroi, J. Chem. Phys. 48, 962 (1968); E. Hirota, S. Saito, and Y. Endo, ibid. 71, 1183 (1979).

${ }^{34}$ O. J. Sovers, C. W. Kern, R. M. Pitzer, and M. Karplus, J. Chem. Phys. 49, 2592 (1968); Y. R. Mo and J. L. Gao, Acc. Chem. Res. 40, 113 (2007).

${ }^{35}$ S. Scheiner, Annu. Rev. Phys. Chem. 45, 23 (1994)

${ }^{36}$ S. S. Xantheas, C. J. Burnham, and R. J. Harrison, J. Chem. Phys. 116, 1493 (2002)

${ }^{37}$ W. Klopper, J. van Duijneveldt-van de Rijdt, and F. B. van Duijneveldt, Phys. Chem. Chem. Phys. 2, 2227 (2000).

${ }^{38}$ S. K. Min, E. C. Lee, H. M. Lee, D. Y. Kim, D. Kim, and K. S. Kim, J. Comput. Chem. 29, 1208 (2008).

${ }^{39}$ J. A. Anderson, K. Crager, L. Fedoroff, and G. S. Tschumper, J. Chem. Phys. 121, 11023 (2004).

${ }^{40}$ J. B. Anderson, J. Chem. Phys. 120, 9886 (2004).

${ }^{41}$ V. E. Bondybey and J. H. English, J. Chem. Phys. 80, 568 (1984).

${ }^{42}$ S. Tsuzuki, T. Uchimaru, M. Mikami, and K. Tanabe, J. Chem. Phys. 109, 2169 (1998)

${ }^{43}$ R. Bukowski, J. Sadlej, B. Jeziorski, P. Jankowski, and K. Szalewicz, J. Chem. Phys. 110, 3785 (1999).

${ }^{44}$ H. S. Gutowsky, T. Emilsson, and E. Arunan, J. Chem. Phys. 99, 4883 (1993).

${ }^{45}$ R. A. DiStasio, Jr., G. von Helden, R. P. Steele, and M. Head-Gordon, Chem. Phys. Lett. 437, 277 (2007).

${ }^{46}$ J. Sponer, P. Jurecka, and P. Hobza, J. Am. Chem. Soc. 126, 10142 (2004).

${ }^{47}$ A. B. T. I. K. Yanson and L. F. Sukhodub, Biopolymers 18, 1149 (1979); C. Fonseca Guerra, F. M. Bickelhaupt, J. G. Snijders, and E. J. Baerends, J. Am. Chem. Soc. 122, 4117 (2000); J. Sponer, J. Leszczynski, and P. Hobza, J. Phys. Chem. 100, 1965 (1996).

${ }^{48}$ K. A. Peterson and J. T. H. Dunning, J. Chem. Phys. 102, 2032 (1995).

${ }^{49}$ S. Tsuzuki and H. P. Luthi, J. Chem. Phys. 114, 3949 (2001).

${ }^{50}$ M. Meot-Ner and C. V. Speller, J. Phys. Chem. 90, 6616 (1986).

${ }^{51}$ S. Hoyau and G. Ohanessian, Chem. Phys. Lett. 280, 266 (1997); J. Am. Chem. Soc. 119, 2016 (1997).

${ }^{52}$ N. Gresh, C. Policar, and C. Giessner-Prettre, J. Phys. Chem. A 106, 5660 (2002).

${ }^{53}$ J. Poater, M. Sola, A. Rimola, L. Rodriguez-Santiago, and M. Sodupe, J. Phys. Chem. A 108, 6072 (2004).

${ }^{54}$ E. I. Solomon, S. I. Gorelsky, and A. Dey, J. Comput. Chem. 27, 1415 (2006).

${ }^{55}$ A. B. Sannigrahi, P. K. Nandi, and P. V. Schleyer, J. Am. Chem. Soc. 116, 7225 (1994).

${ }^{56}$ JANAF Thermochemical Tables, $3 r d$ Ed., edited by M. W. Chase, Jr., C. A. Davies, J. R. Davies, Jr., D. J. Fulrip, R. A. McDonald, and A. N. Syverud, J. Phys. Chem. Ref. Data 14, Supplement 1, 1985. 